Published in final edited form as:

Nat Rev Cancer. 2008 June ; 8(6): 425-437. doi:10.1038/nrc2397.

\title{
Cycling hypoxia and free radicals regulate angiogenesis and radiotherapy response
}

\author{
Mark W. Dewhirst, Yiting Cao, and Benjamin Moeller \\ Department of Radiation Oncology, Duke University Medical Center, Durham, North Carolina \\ 27710, USA.
}

\begin{abstract}
Hypoxia and free radicals, such as reactive oxygen and nitrogen species, can alter the function and/or activity of the transcription factor hypoxia-inducible factor 1 (HIF1). Interplay between free radicals, hypoxia and HIF1 activity is complex and can influence the earliest stages of tumour development. The hypoxic environment of tumours is heterogeneous, both spatially and temporally, and can change in response to cytotoxic therapy. Free radicals created by hypoxia, hypoxia-reoxygenation cycling and immune cell infiltration after cytotoxic therapy strongly influence HIF1 activity. HIF1 can then promote endothelial and tumour cell survival. As discussed here, a constant theme emerges: inhibition of HIF1 activity will have therapeutic benefit.
\end{abstract}

\begin{abstract}
Virchow first described the abnormal structure of tumour vessels using contrast agents in human tumours as early as the mid $1800 \mathrm{~s}^{1}$. A few decades later, Goldman was among the first to suggest that angiogenesis was associated with tumour growth ${ }^{2}$. A number of other investigators in the nineteenth and early twentieth centuries evaluated tumour angiogenesis, using techniques such as microangiography, vascular casting and window chamber models. Warren has reviewed this early work in great detail ${ }^{3}$. Folkman illuminated the crucial role of tumour angiogenesis by hypothesizing that tumour growth was dependent upon angiogenesis and that, if angiogenesis could be inhibited, it could maintain tumour deposits in a quiescent state ${ }^{4}$. These early works set the stage for the concept that tumours require angiogenesis to provide a nutrient supply. Although it is well-established that angiogenesis occurs in nearly all human solid tumours, it does not occur in an efficient manner, leading to spatial and temporal inadequacies in delivery of oxygen and other nutrients. These inefficiencies in nutrient delivery lead to a brutal cycle of unsatisfied demand by the tumour, which drives continued aberrant angiogenesis.
\end{abstract}

The transcription factor hypoxia-inducible factor 1 (HIF1) plays an important part in tumour progression by upregulating genes that control angiogenesis, meta-stasis and resistance to oxidative stress. It also controls the switch to anaerobic metabolism, which can maintain cell

\author{
() 2008 Macmillan Publishers Limited. All rights reserved. \\ Correspondence to M.W.D. dewhi001@mc.duke.edu. \\ DATABASES \\ Entrez Gene: http://www.ncbi.nlm.nih.gov/entrez/query.fcgi?db=gene \\ angiotensin | ANGPT2 | ARNT | CA9 | CREBBP | EGFR | EGLN1 | FGF2 | FRAP1 | HIF1a | HRAS | involucrin | lysyl oxidase | \\ NOS3 | PTEN | SERPINE | SOD1 | SOD2 | SPP1 | TFAM | thrombin | thrombospondin 1| TP53 \\ National Cancer Institute: http://www.cancer.gov/ breast cancer $\mid$ cervical cancer $\mid$ colorectal cancer $\mid$ glioma $\mid$ head and neck cancer \\ National Cancer Institute Drug Dictionary: http://www.cancer.gov/drugdictionary/ tirapazamine \\ FURTHER INFORMATION \\ M. W. Dewhirst's homepage: http://pathology.mc.duke.edu/website/webform.aspx?id=GradDewhirst \\ SUPPLEMENTARY INFORMATION See online article: $\underline{\mathrm{S} 1}$ (movie) $\mid \underline{\mathrm{S} 2}$ (movie) $\mid \underline{\mathrm{S} 3}$ (figure) \\ ALL LINKS ARE ACTIVE IN THE ONLINE PDF
}


viability under hypoxic conditions. Further, HIF1 activity can promote treatment resistance by promoting endothelial and tumour cell survival after cytotoxic therapy. The mechanisms that control HIF1 activity are complex and are influenced by microenvironmental factors involving hypoxia, oxidative and nitrosative stress.

In this Review we will discuss four important and interrelated aspects of tumour hypoxia. First, we will define the hypoxic response, discussing its relevance in influencing tumour cell survival, behaviour and angiogenesis. We will examine the physiological factors that contribute to hypoxia, emphasizing a perspective based on spatial and temporal dysfunction of tumour microcirculation. The question of whether hypoxia is involved in angiogenesis initiation and the role that this might have in angiogenesis remodelling during tumour growth will be discussed. Finally, we will discuss how cytotoxic therapies, such as radiation treatment, affect tumour and endothelial cell survival, with an emphasis on a regulatory axis between hypoxia and free radicals and HIF1.

\section{Regulation of HIF1 by hypoxia}

The term hypoxia is most accurately described as an oxygenation state that is below the norm for a particular tissue. The average partial pressure of $\mathrm{O}_{2}\left(\mathrm{pO}_{2}\right)$ of normal tissues usually exceeds $20 \mathrm{mmHg}^{5,6}$. When $\mathrm{pO}_{2}$ falls below $10 \mathrm{mmHg}$, cells typically increase production of many genes regulated by the hypoxia-inducible transcription factor HIF1 (REF. 7). HIF1 consists of $\alpha$ and $\beta$ subunits, which heterodimerize and bind to DNA at hypoxia response elements (HREs) in promoter or enhancer regions of numerous genes to upregulate their transcription ${ }^{7-9}$. These families of genes initiate anaerobic metabolism, increase angiogenesis, protect cells against oxidative stress and promote a greater degree of invasiveness and motility (FIG. 1). The HIF1a subunit is exquisitely regulated by hydroxylation of proline residues in its oxygen-dependent degradation domain (ODD) that target it for recognition by the von Hippel lindau (VHl) complex and subsequent proteasomal degradation under aerobic conditions ${ }^{10,11}$. A family of prolyl hydroxylases (PHDs) that require molecular oxygen to perform their function are responsible for the hydroxylation of HIF1a ${ }^{7}$.

Although most tissues exist at $\mathrm{pO}_{2}$ levels exceeding $20 \mathrm{mmHg}$, there are some tissues that exist at lower $\mathrm{pO}_{2}$. Examples of relatively hypoxic normal tissues include pericentral vein cells in the liver ${ }^{12}$, portions of the retina (in the dark) ${ }^{13}$, spinous layer of the epidermis ${ }^{14}$, the thymus ${ }^{6,15}$, renal tubular epithelium ${ }^{16}$, myocardium (particularly during exercise) ${ }^{17}$ and subregions of the bone marrow that are enriched for stem cells ${ }^{18}$. Hypoxia has diverse roles in the function of these normal tissues. Hepatocytes surrounding the central vein have been shown to be hypoxic ${ }^{19,20}$, and their location coincides with overexpression of vascular endothelial growth factor (VEGF) and basic fibroblast growth factor (bFGF, also known as $\underline{\text { FGF2 }})^{21}$. In an unperturbed state, there is no angiogenesis, so the cytokines are probably bound to proteoglycans, which maintain them in an inactive state 22,23 . However, the inactive forms can be rapidly released after injury or stress to promote angiogenesis.

Hypoxia might be involved in squamous epithelial cell maturation in the skin. A regulator of epithelial differentiation, involucrin, is upregulated under hypoxic conditions in vitro and its expression coincides with hypoxia marker drug binding in immunohistochemical evaluation of skin samples ${ }^{24}$. In the bone marrow the role of hypoxia is reversed relative to what is observed in skin. Here, the most primitive stem cells are maintained in a hypoxic niche ${ }^{18}$. These cells are maintained in a quiescent state by hypoxia-regulated proteins, such as osteopontin (encoded by $\underline{S P P I})^{18,25}$. The stem cells are prone to use anaerobic metabolism, perhaps as a means to reduce genotoxic stress associated with reactive oxygen species generated from aerobic metabolism ${ }^{18}$. Oxygen electrode and hypoxia marker drug studies 
have demonstrated that the thymus of mice is heterogeneously hypoxic ${ }^{6,15}$, but in this tissue there is no evidence for HIF1-regulated gene expression ${ }^{15}$. Recently it was shown that lymphocyte motility in lymph nodes is affected by $\mathrm{pO}_{2}$, with motility decreasing with oxygen content ${ }^{26}$. Thus, hypoxia in the thymus might serve to keep maturing lymphocytes within the thymus until they are ready to be released. Maintenance of hypoxia in the thymus could also have a role in protecting thymocytes from genotoxic stress.

\section{Regulation of HIF1 by free radicals}

HIF1 has been referred to as the "master regulator of oxygen homeostasis"7, but it is regulated by many factors aside from hypoxia, including oncogenes, growth factors and free radicals ${ }^{27-29}$. Free radicals are chemical species that contain unpaired electrons; of particular importance here are oxygen-containing radicals, such as the superoxide anion $\left(\mathrm{O}_{2}{ }^{-}\right)$. The reactive oxygen molecule hydrogen peroxide $\left(\mathrm{H}_{2} \mathrm{O}_{2}\right)$, the end product of enzymatic conversion of $\mathrm{O}_{2}^{-}$by superoxide dismutase (SOD), is also important in the regulation of HIF1 (REFS 28,30). Nitric oxide (NO), also a free radical, is a multifunctional biological gas that is an important cell signalling molecule at low concentrations but can be cytotoxic at high concentrations ${ }^{31,32}$. There are three isoforms of nitric oxide synthase that produce NO from 1-arginine ${ }^{33}$. Nitric oxide synthases are overexpressed in many forms of human cancer ${ }^{34,35}$, in tumour cells and/or in infiltrating macrophages. The role of reactive oxygen species in regulating HIF1 activity is at least as important as hypoxia per se and is far more complex than hypoxia itself.

It is important to consider free radical regulation of HIF1 in the context of the oxygenation state of the cells, the concentration of each species and which species are involved. As will be discussed below, there are multiple sources of reactive oxygen and nitrogen species in tumours and these can clearly influence HIF1 activity in ways that are independent of hypoxia.

\section{Free radical regulation of HIF1 under aerobic conditions}

Increased levels of SOD1 in pulmonary artery smooth muscle cells has been shown to increase levels of reactive oxygen species and stabilize HIF1a, and this effect is dependent upon the activity of catalase. When catalase is overexpressed, stabilization of HIF1a disappears, indicating that $\mathrm{H}_{2} \mathrm{O}_{2}$ is required for the response ${ }^{36}$. Angiotensin II and thrombin can stimulate generation of free radical species and mimic the effects of hypoxia to upregulate HIF1a levels and activity. It has recently been shown that angiotensin II mediates this effect by increasing the levels of $\mathrm{H}_{2} \mathrm{O}_{2}$, which depletes intracellular stores of ascorbate, an important co-factor involved in PHD activity ${ }^{37}$. Thus, $\mathrm{H}_{2} \mathrm{O}_{2}$, the product of $\mathrm{O}_{2}{ }^{-}$dismutation by sOD, is one candidate likely to be responsible for stabilization of HIF1a under aerobic conditions.

NO can influence the levels of HIF1a in complex ways. Mateo and moncada reported that NO concentration has a strong influence on whether HIF1 is stabilized under aerobic conditions $^{38}$. Human HEK-293 cells were stably transduced with an inducible nitric oxide synthase (iNOs), under control of the tetracycline promoter. By varying the amount of tetracycline in media, they were able to control NO concentrations and increased HIF1a protein levels were observed when NO concentrations exceeded $5 \mu \mathrm{m}$. There are two potential mechanisms for this effect. Exposure to NO has been shown to nitrosylate thiols in the HIF1a protein leading to HIF1a stabilization under aerobic conditions ${ }^{39}$. Recently, the specific target has been identified to be a cysteine residue in the ODD of HIF1a, which blocks its binding to the $\mathrm{VHl}$ complex for subsequent degradation ${ }^{27}$. NO can promote binding of HIF1 to HREs in HIF1 target genes by binding to an adjacent HIF1 ancillary sequence (HAs) and hence acting as a transcriptional co-activator ${ }^{40}$. It has also been 
reported that $\mathrm{NO}$ can upregulate the rate of HIF1a synthesis by activating the phosphatidylinositol 3-kinase (PI3K)-mAPK (mitogen-activated protein kinase) pathway $^{41,42}$.

\section{Free radical regulation of HIF1 under hypoxic conditions}

Schumacker and Chandel have theorized that the oxygen sensor in cells is not the PHD but rather the formation of reactive oxygen species by mitochondria under hypoxia that lead to stabilization of HIF1a ${ }^{28,30}$. Evidence for this mechanism of stabilization of HIF1 is multifold. First, $\rho^{0}$ cells, chemically depleted of functional mitochondria, cannot increase HIF1a levels in response to hypoxia ${ }^{28}$. Second, overexpression of catalase blocks hypoxic stabilization of HIF1a, whereas administration of $\mathrm{H}_{2} \mathrm{O}_{2}$ to cells increases HIF1 expression $^{28}$. Recently, a genetic approach has been taken to further test the hypothesis that reactive oxygen species are important in hypoxic signalling for HIF1a stabilization and hypoxia signalling. It has been reported that mitochondrial complex III may be important in this pathway. Cells in which complex III activity has been knocked down through RNA interference-mediated reduction of expression of one of the protein subunits of this complex show decreased reactive oxygen species formation and decreased HIF1a expression levels ${ }^{29}$. When $\mathrm{H}_{2} \mathrm{O}_{2}$ is added back, the knockdown cells regain the ability to stabilize HIF1a under hypoxia. This result suggests that electron flow through complex III is required for hypoxic stabilization of HIF1a. Cytochrome $c$, which is responsible for shuttling electrons between complex II and complex III, might be central to this sensing mechanism. Mouse embryonic fibroblasts depleted of cytochrome $c$ are completely incapable of eliciting an increase in HIF1a in response to hypoxia, but these same cells show strong induction of HIF1a after exposure to $\mathrm{H}_{2} \mathrm{O}_{2}$ (REF. 43). Similarly, cells in which mitochondrial transcription factor A (TFAm) is knocked down, rendering them incapable of making mitochondria, cannot produce reactive oxygen species nor can they stabilize HIF1a under hypoxic conditions ${ }^{30}$. Finally, overexpression of manganese superoxide dismutase (MnSOD, also known as $\underline{\mathrm{SOD}}$ ), the mitochondrial SOD, has been shown to inhibit HIF1a levels, downregulate VEGF and inhibit tumour growth ${ }^{44,45}$.

The effects of NO in controlling HIF1 activity under hypoxic conditions are complex. The initial report indicated that NO inhibits stabilization of HIF1 under hypoxia ${ }^{46}$. The underlying mechanism for this effect does not appear to be mediated by nitrosylation of the cysteine residue in the ODD, although deletion of the ODD eliminates the effect of NO in downregulating HIF1a protein levels ${ }^{47}$. As detailed above, under aerobic conditions, NO nitrosylates this residue to prevent degradation of HIF1 (REF. 27). Using reporter genes that were targeted to either mitochondria or cytosol, Hagen demonstrated that NO inhibits respiration by inhibiting cytochrome $c$ oxidase activity under hypoxic conditions, thereby permitting increased PHD activity as oxygen is redistributed to the cytosol ${ }^{48}$. Recently it has been reported that NO elicits a feedback regulatory mechanism between HIF1 and PHD2 (also known as EGLN1) ${ }^{49}$. When cells are first exposed to NO, HIF1a levels transiently increase, stimulating increased expression of PHD2. Increased levels of PHD2 can then feed back to inhibit HIF1a levels. In summary, the regulation of HIF1 by NO under hypoxic conditions centres on modification of the ODD, but might involve redistribution of residual oxygen from the mitochondria to the cytosol.

In summary, the roles that free radical species have in controlling HIF1a levels and HIF1 transcriptional activity are complex and interrelated. We have presented this story in four categories, segregating hypoxia and normoxia and reactive oxygen species and nitric oxide. However, it is likely that all of these pathways and factors are active simultaneously in tumours, with micro-regional and temporal variations. However, as discussed below, the 
role of reactive oxygen species in regulating HIFla might overshadow the effect of hypoxia per se on HIF1a expression.

In cervical cancer it has been shown that there is good correlation between the expression of HIF1 targets and the hypoxia marker drug, pimonidazole ${ }^{50}$, but in other reports there has been poor correlation between HIF1 or its regulated cytokine VEGF ${ }^{51}$ and localization of hypoxia marker drugs ${ }^{52,53}$. Given the complexities involved in regulating HIF1a, as outlined above, it comes as no surprise that there is generally a lack of correlation between hypoxia and HIF1 levels in tumours. In head and neck cancer it has recently been reported that HIF1a expression levels tracked with expression of eNOs (also known as nitric oxide synthase $3\left(\text { NOS3 }_{)}\right)^{54}$, indicating that NO levels might independently regulate HIF1a levels. As will be discussed below, the complexities of oxygen transport and angiogenesis in tumours will also probably contribute to heterogeneity in the regulation of HIF1 activity and consequently correlations between HIF1a expression and hypoxia.

\section{Origins of hypoxia in solid tumours}

The presence of hypoxia in tumours is a well-established source of resistance to radiation therapy and chemotherapy ${ }^{55}$. In the case of radiation therapy, this is known to be related to the effect of oxygen in stabilizing DNA damage from radiation in a form that is not easily repaired. The activity of many chemotherapeutic drugs is also altered at low oxygen concentration, at which the percentage of cycling cells is relatively low and drug delivery may be compromised ${ }^{55}$. Overexpression of HIF1a, driven by hypoxia and free radical species, will also contribute to therapy resistance. Thus, it is important to understand the underlying mechanisms that contribute to failure to deliver adequate oxygen and other nutrients to tumour cells. There are several methods to measure hypoxia in tumours (BOX $1)$.

\section{Deficiencies in oxygen transport}

The oxygenation state of any location in a tissue is the result of a balance between delivery and consumption of oxygen. There are several excellent reviews on this subject $5,56,57$. The deficiencies of oxygen transport can be summarized as having eight dominant features: first, a relatively sparse arteriolar supply 5,58 ; second, inefficient orientation of microvessels ${ }^{59,60}$; third, low vascular density; fourth, extreme variations in microvessel red blood cell flux (many tumour vessels do not carry red blood cells, whereas large diameter shunt vessels contain a relative abundance of red blood cells ${ }^{61}$ ); fifth, the limited arteriolar supply can lead to pathologically low vascular $\mathrm{pO}_{2}$ in regions distant from the arteriolar source (longitudinal oxygen gradient) ${ }^{58,62,63}$; sixth, hypoxic red blood cells stiffen, increasing blood viscosity, which contributes to sluggish flow; and seventh, large diameter shunts can divert blood away from the tumour bed. Consequently, networks of microvessels can exhibit low $\mathrm{pO}_{2}$, leading to relatively large regions of tumour that are dominated by microregions of pathologically low $\mathrm{pO}_{2} 58,62,64-66$ (FIG. 2).

The seven features discussed above influence the overall oxygenation state of a tumour, but an important feature of tumour hypoxia is that it is unstable. The eighth dominant feature of tumour hypoxia is that it is cyclical, a phenomenon proposed almost 30 years ago ${ }^{67-69}$. This feature of tumour pathophysiology has often been referred to as "intermittent" or "perfusion limited" hypoxia ${ }^{70,71}$. We believe that a more precise definition might be 'cycling hypoxia' because this feature demonstrates clear patterns of periodicity across many tumour types ${ }^{70}$. Two of the first studies on this subject used dorsal skin fold window chambers in rats (BOX 2 ), which allowed direct visualization of the developing vasculature of tumours under a microscope in the living animal. Reinhold observed fluctuations in redox ratio in tumour tissues. The redox ratio is derived from the ratio of fluorescence of endogenous molecular 
species involved in respiration and thereby reflects oxygenation status ${ }^{68}$. Yamaura observed vascular stasis in microvessels in skin fold window chamber tumours near regions of tumour regrowth after radiation therapy. He surmised that tumour cells near such vessels would become hypoxic during vascular stasis. If stasis happened during radiotherapy, it could be responsible for hypoxic radioresistance ${ }^{69}$. Martin Brown was the first to demonstrate that intermittent hypoxia could actually be a cause for radioresistance. He selectively killed hypoxic EmT6 tumour cells in mice with a hypoxic cytotoxin and $24 \mathrm{~h}$ later found reemergence of a radiobiologically significant hypoxic fraction ${ }^{67}$.

\section{Kinetics}

There is strong evidence that the kinetics of cycling hypoxia are complex, with at least two dominant timescales. One has a frequency of a few cycles per hour and the second exhibits variations on a timescale of hours to days. These two frequencies superimpose on each other to yield a complex timescale for fluctuations. An analogy is the relationship between the tides and waves in the ocean. Both occur at the same time, but the waves have a higher frequency than the tides. Also, the tides influence how high the waves wash up onto the shore. In the same way, the degree of hypoxia is influenced by the overall oxygenation state of large tumour regions (analogous to tides), superimposed on higher frequency instabilities (analogous to waves) that are caused primarily by fluctuations in microvessel red blood cell flux.

The higher frequency cycles were described first. Chaplin and co-workers defined a dominant periodicity for flow instability and radioresistance of around $20 \mathrm{~min}$ for a variety of different preclinical tumour models ${ }^{72-76}$. In their first experiments, the investigators administered a dye that binds to the nuclei of cells surrounding micro-vessels to animals either simultaneously with or sequentially with radiation treatment ${ }^{77}$. Following irradiation, the tumours were excised and sorted by perfusion dye intensity using flow cytometry. The brightest cells and dimmest cells were assumed to be most proximal and distal to microvessels, respectively. The fraction of tumour cells surviving was determined for each cohort of cells (classified by dye staining intensity). When the dye and irradiation were given simultaneously, the dimmest cells were the most radioresistant, but when there was a 20 min time delay between dye and irradiation, there was no relationship between dye staining intensity and radiosensitivity. The conclusion was that the cells that were hypoxic at time zero were no longer hypoxic 20 min later.

Durand administered two perfusion marker dyes, either simultaneously or separated in time by periods of up to $30 \mathrm{~min}^{71,78,79}$. He observed regions of dye mismatch in frozen sections of tumour samples when the dyes were administered with a time delay. He also observed differences in perfusion marker dye fluorescence intensity, concluding that variations in blood flow rate may be sufficient to induce changes in the level of hypoxia ${ }^{79}$. Skin fold window chamber tumour studies showed that perivascular $\mathrm{pO}_{2}$ and red blood cell fluxes were temporally synchronized ${ }^{61,80,81}$. Theoretical predictions were that fluctuations in vascular $\mathrm{pO}_{2}$ would influence the $\mathrm{pO}_{2}$ of cells residing several cell layers away from the microvessel. Recently, this prediction was confirmed experimentally, demonstrating for the first time that fluctuations in red blood cell flux are primarily responsible for cycling hypoxia in tumours ${ }^{81}$. Implantable microsensor studies have shown that red blood cell flux and $\mathrm{pO}_{2}$ fluctuate a few cycles per hour in several different tumour lines ${ }^{82-84}$. Similar results have been reported using laser Doppler flowmetry and fibre-optic oxygen sensors in human and canine tumours, respectively 83,85 .

Benne with performed multiple administrations of a hypoxia marker drug to obtain steady state levels of the drug systemically over $8 \mathrm{~h}$. Using flow cytometric analysis of cells taken from the tumour and an antibody to detect the presence of drug-protein adducts, they found 
that the hypoxic fraction increased following chronic administration to a level higher than administration of a single bolus of a similar marker drug. This result suggested that intermittent hypoxia is not relegated to specific subregions within a tumour ${ }^{86}$. When they administered a second hypoxia marker drug $1 \mathrm{~h}$ after the last administration of the first drug, they found a substantial portion of cells that were labelled with one drug but not the other. They observed variation in the fraction of cells experiencing these events in two different tumour lines, but the results suggest that relatively large subregions of tumours can experience transient periods of hypoxia and reoxygenation.

\section{Spatial characteristics of $\mathrm{pO}_{2}$ instability}

Cardenas-Navia et al. used phosphorescence lifetime imaging to serially monitor vascular $\mathrm{pO}_{2}$ in 2-3 mm regions of skin fold window chamber tumours over periods of 60-90 min. The oxygenation state of all microvessels continuously changed in three different tumour lines, with significant differences in the spatial relatedness of the instability ${ }^{87}$ (see supplementary information $\underline{\mathrm{S} 1} \& \underline{\mathrm{S} 2}$ (movies)). Baudelet et al. used serial measurements of blood oxygen level detection (BOLD) magnetic resonance imaging (MRI) to identify rather macroscopic (a few millimetres in diameter) regions that exhibited synchronized fluctuating signals related to the degree of haemoglobin saturation. Sorg measured haemoglobin saturation in networks of tumour microvessels, demonstrating that fluctuations were temporally coordinated in regions of a few hundred microns in dimension ${ }^{88}$. These results indicate that small vascular networks are probably cycling together ${ }^{89}$. Similar results have been reported comparing serial dynamic contrast enhanced (DCe) MRI measurements in human tumour xenografts ${ }^{90}$. These preclinical studies suggest that cycling hypoxia involves relatively large tumour regions that are connected by common microvascular networks.

\section{Mechanisms underlying cycling hypoxia and implications}

The higher frequency hypoxic cycles are caused by variations in red blood cell flux within tumour microvessels ${ }^{80,81,85}$. Fluctuations in feeding arteriolar diameter have been shown to match temporal changes in microvessel red blood cell flux in the same tumour ${ }^{61}$. Similarly, fluctuations in BOID mRI signals have been observed more frequently in tumour regions that contain blood vessels with smooth muscle ${ }^{91}$. Thus, some of the fluctuations in red blood cell flux might be due to vasomotion of resistance vessels. Using serial observations of tumour microvessels in window chambers, Patan identified vascular intussusception, a process in which microvessels remodel to split into parallel smaller vessels ${ }^{92}$. This process occurred over periods of tens of minutes, which is consistent with the time frame for the high frequency cycling hypoxia. Flow resistance $(\mathrm{R})$ is inversely proportional to vessel radius to the fourth power $\left(\mathrm{R}=8 \eta^{\prime} / \pi \mathrm{r}^{4} \text {; where } \eta^{\prime}=\text { viscosity and } \mathrm{r}=\text { vessel radius }\right)^{93}$. Thus, as a microvessel splits, it will reduce flow in the two vascular segments disproportionally to the split in diameter, leading to redistribution of flow within the network. It is important to note that even small perturbations in microvessel diameter in a small proportion of vessels within a network can profoundly influence haemodynamics within an entire network ${ }^{94,95}$. Uneven distribution of red blood cells at microvessel bifurcation points would be more exaggerated in tumours than normal tissues because hypoxic red blood cells are less deformable, which increases blood viscosity ${ }^{96}$.

Using window chamber tumours, we have observed dynamic changes in microvascular structure on a daily basis. Sometimes, the vascular network changed so dramatically that the same microvessels could not be observed serially ${ }^{97}$. These results suggest that vascular remodelling might be responsible for the slower frequency of cycling hypoxia. Recent ${ }^{18} \mathrm{~F}$ misonidazole (a hypoxia marker drug) positron-emission tomography (PET) studies in human patients with head and neck cancer have verified that large regions of tumours can experience the slower frequency cycling hypoxia ${ }^{98}$. In these studies, serial PET studies 
scheduled 3 days apart showed that hypoxic tumour zones moved or changed in size between sequential studies.

The primary consequence of cycling hypoxia is upregulation of HIF1 activity to a level that supersedes that of chronic hypoxia. Peng et al. examined HIF1 expression in the carotid body following 10 days of repeated $15 \mathrm{~s}$ exposures to $5 \% \mathrm{O}_{2}$, followed by breathing air. They observed significant upregulation of HIF1a levels in carotid bodies of mice ${ }^{99}$. Similar results were seen in vitro with the PC12 cell line ${ }^{100}$. The mechanism of enhanced HIF1 activity is multifactorial, stemming from alteration in the rate of HIF1a synthesis, regulated by mTOR (also known as FRAP1), and phosphorylation of the HIF1 binding cofactor CBP (also known as p300 and CREBBP) ${ }^{101}$. Repeated exposure of endothelial cells to hypoxia and reoxygenation can lead to much greater upregulation of HIF1a than can be achieved by chronic exposure to hypoxia. This effect may be regulated by increased phosphorylation of HIF1a ${ }^{102,103}$. Cycling hypoxia can also be expected to increase levels of free radicals, as a result of hypoxia-reoxygenation injury. Activation of the xanthine oxidase pathway during hypoxia-reoxygenation injury results in release of $\mathrm{H}_{2} \mathrm{O}_{2}$, secondary to lipid peroxidation. As discussed above, $\mathrm{H}_{2} \mathrm{O}_{2}$ can stabilize HIF1a.

\section{Features of cycling tumour hypoxia}

The model that we propose incorporates vascular geometry, radial diffusion of oxygen from vessels, distribution of red blood cells at bifurcation points and instabilities in red blood cell flux, all of which can lead to dynamic changes in the oxygenation of dependent tumour cells (FIG. 3). These features represent the higher frequency waves of cycling hypoxia. The location, shape and steepness of the oxygen gradient, which is influenced by vascular density and proximity to the arteriolar source, will vary according to how the structure of the larger vascular network changes over time. Remodelling of the networks occurs on a slower timescale and would result in the slower tidal cycling of hypoxia. As both chronic and cycling hypoxia can influence HIF1 transcriptional activity, it is expected that there will be phenotypical changes in cells as a consequence. One of the primary consequences might be alterations in angiogenesis, as most pro-angiogenenic factors are regulated by HIF1.

\section{Hypoxia and angiogenesis}

There is considerable evidence that upregulation of the HIF1-regulated protein VEGF and other factors such as angiopoeitin 2 (ANGPT2) promote the initiation and promulgation of angiogenesis. Other angiopoeitins also have a role ${ }^{104-115}$. The 'angiogenic switch' describes a collection of circumstances under which angiogenesis can be initiated, which is determined by a balance of proand anti-angiogenic factors. Importantly, hypoxia has been thought of as a primary trigger that tips the balance toward angiogenesis, as it will increase HIF1 activity and hence VEGF levels ${ }^{115-117}$. As many cytotoxic treatments change tumour oxygenation, it might be expected that treatments may also influence the angiogenic response of a tumour.

Oncogenic regulation of angiogenesis has also been suggested, either alone or working in combination with hypoxia, to stimulate angiogenesis. For example, upregulation of $\underline{\mathrm{HRAS}}$ and epidermal growth factor receptor $(\underline{E G F R})^{118,119}$ and inactivation of the tumour suppressor gene TP53 (REFS 120,121), can increase rates of synthesis of HIF1a to a level that overwhelms the capacity of the degradation pathway to eliminate $\mathrm{it}^{122}$. The increase in HIF1 synthesis appears to be regulated by the PI3K-AKT pathway ${ }^{123}$.

VEGF upregulation is a trigger for initiation of angiogenesis from dormant metastases and the angiogenesis inhibitor thrombospondin 1 might inhibit VEGF activity to promote dormancy $^{124}$. Hypoxia, on the other hand will increase HIF1 activity to upregulate VEGF 
while downregulating thrombospondin, to create a pro-angiogenic environment ${ }^{117}$. Some metastatic tumours replace normal parenchymal cells with tumour cells thereby co-opting normal vasculature. For example, human breast tumours that have metastasized to liver show this phenotype. They have been reported to exhibit little evidence for hypoxia (indicated by expression of the endogenous hypoxia marker protein carbonic anhydrase IX) and express low levels of VEGF ${ }^{125,126}$. Hepatic metastases of colorectal cancer, by contrast, show high levels of carbonic anhydrase IX and increased VEGF and clearly exhibit angiogenesis ${ }^{125}$.

In the case of primary tumours, growth beyond a few millimetres is unusual in the absence of angiogenesis. As an example, consider the case of intraductal breast cancer (ductal carcinoma in situ). These lesions are multifocal with typical diameters of 200-300 $\mu \mathrm{m}$. Bos et al. examined HIF1a expression in ductal carcinoma in situ lesions and found that HIF1a and VEGF expression and angiogenesis were not apparent in hyperplasia. The frequency of tumours with positive HIF1 expression increased proportionally with tumour grade; VEGF expression and angiogenesis tracked with HIF1 expression ${ }^{127}$. These data are consistent with HIF1 driving VEGF production and angiogenesis in these early lesions. However, it is not known whether hypoxia-induced stabilization of HIF1a has a dominant role in the initiation of angiogenesis because of the multiple regulatory mechanisms of HIF1a expression and activity that could be involved (such as the presence of free radicals or oncogenic regulation).

Holash et al. performed elegant experiments using an intracranially transplanted C6 glioma model to examine whether there was evidence for hypoxia-driven angiogenesis initiation ${ }^{109}$. The experiments were performed by transplanting the tumour cells into the brain of recipient rats and then examining the tissues histologically at set time points after transplant. They observed vessel cooption in the first week after tumour transplantation, which was characterized by histological evidence of tumour cells infiltrating around pre-existing normal vessels. Immunohistochemical data showed breakdown of vascular basement membrane and vessel regression during week 2 , and by week 4 there was clear evidence of vasodilation and new vessel formation interspersed with islands of necrosis. In situ hybridization showed increased Angpt2 mRNA expression before the upregulation of VEGF. This was also observed in a rat mammary carcinoma and in lung metastases from lewis lung carcinoma. They hypothesized that vascular shutdown, caused by ANGPT2mediated de-differentiation of microvessels, in the absence of VEGF (and hence angiogenesis), led to hypoxia. Thus, in their model, a 'hypoxic crisis' was responsible for the initial upregulation of VEGF and onset of angiogenesis.

We used the mouse dorsal skin fold window chamber model to address the same question. Window chambers were implanted with murine and human tumour cell lines, stably transfected with two reporter genes: red fluorescent protein under control of a constitutive $\mathrm{CmV}$ promoter $\left(\mathrm{RFP}_{\mathrm{c}}\right)$, and green fluorescent protein under control of an HRE derived from the VEGF promoter region $\left(\mathrm{GFP}_{\mathrm{h}}\right)^{97}$. Angiogenesis occurred before detection of $\mathrm{GFP}_{\mathrm{h}}$, typically by 1-2 days. The hypoxic cytotoxin tirapazamine delayed the detection of $\mathrm{GFP}_{\mathrm{h}}$, but had no effect on angiogenesis initiation. Both tumour lines expressed VEGF at low levels under normoxia, but several hours of hypoxia significantly increased VEGF expression in vitro. In contrast to Holash's theory, we did not observe vascular stasis before angiogenesis onset, but angiogenesis was accelerated when HIF1a was upregulated. Thus, we term our model the 'acceleration model'. We propose that HIF1a upregulation accelerates tumour angiogenesis, as opposed to its having a role in the initiation stages. There is a normal tissue corollary to this, based on wound healing. In a rat dermal skin wound model, hypoxia was not involved in the initiation of angiogenesis; rather, it was associated with the period of wound involution after reepithelialization ${ }^{14}$. In an analogous 
fashion, HIF1 upregulation and increases in VEGF in response to tumour hypoxia may be important in vascular remodelling during continued tumour growth ${ }^{128}$. In summary, results from in vivo window chamber and wound healing models are not consistent with the vascular crisis theory of Holash, and instead point to a role for hypoxia in angiogenesis acceleration and remodelling (FIG. 4). Because the results from the studies presented above came from different tumour models, more efforts are needed in a broad range of tumour models to further elucidate the role of hypoxia in the initiation and/or acceleration of tumour angiogenesis.

\section{HIF1 regulation after angiogenesis initiation}

To further establish the interrelationship between angiogenesis and oxygen delivery we used optical methods to directly measure haemoglobin saturation of microvessels in the same tumours in which we measured $\mathrm{GFP}_{\mathrm{h}}$ expression. In the earliest stages of tumour growth, $\mathrm{GFP}_{\mathrm{h}}$ was found in regions relatively devoid of vasculature (hypoxic). As tumour growth continued, however, we often observed relatively high expression of $\mathrm{GFP}_{\mathrm{h}}$ in the immediate vicinity of microvessels ${ }^{63}$. We knew that these vessels were relatively well-oxygenated because $\mathrm{Hb}_{\text {sat }}$ levels indicated sufficient $\mathrm{O}_{2}$ supply (see supplementary information $\underline{\mathrm{S} 3}$ (FIGURE)). Therefore, reactive oxygen species and/or NO might be stabilizing HIF1a in perivascular tumour cells. This scenario could further accelerate angiogenesis and vascular remodelling as a result of high perivascular VEGF concentrations.

\section{Effects of radiation therapy on HIF1 activity}

It is well-established that hypoxic tumours will reoxygenate after treatment with radiation and some forms of chemotherapy ${ }^{129-133}$. The effect is probably caused by reduction in oxygen consumption rate as a result of death of the more radiosensitive oxygenated tumour cells in addition to an increase in perfusion ${ }^{130,134,135}$. We used the $\mathrm{RFP}_{\mathrm{c}}$ and $\mathrm{GFP}_{\mathrm{h}}$ cell lines described above to evaluate the effects of radiation therapy on HIF1 activity ${ }^{136}$. It was expected that reporter gene expression would decrease after radiation treatment, commensurate with improved oxygenation. However, the opposite effect was observed: $\mathrm{GFP}_{\mathrm{h}}$ reporter activity actually increased up to $72 \mathrm{~h}$ after treatment. This was confirmed by showing that HIF1a protein levels increased, along with several HIF1-regulated proteins. Two independent mechanisms were found to be responsible for this effect. First, increased free radicals after radiation: if the accumulation of these radicals was inhibited using a manganese porphyrin sOD mimetic, the stabilization of HIF1a was prevented and the tumour microvasculature was sensitized to radiation damage. Antisense knockdown or pharmacological inhibition of HIF1 synthesis after radiation treatment was shown to also induce significant growth delay in several tumour lines by our group ${ }^{136-138}$. In a separate study, Williams et al. showed prolonged tumour growth after radiotherapy in a tumour line that is null for HIF1 $\beta$ (also known as ARNT), and therefore unable to render a HIF1 response $^{139}$. The second mechanism of HIF1a stabilization after reoxygenation was related to stress granules ${ }^{140}$. These are protein-mRNA complexes that form in cells during periods of stress and prevent the cell from using energy for protein translation. Stress granule formation coincided with hypoxia in vivo and in vitro and disaggregated during reoxygenation, releasing HIF1-regulated transcripts. When stress granule formation was blocked by using an antisense against one of the key proteins involved in forming the stress granule, HIF1-mediated gene expression was reduced ${ }^{136}$.

Recently, in collaboration with Chuan li's group, we found another pathway for HIF1a stabilization after radiation therapy. A second peak of HIF1a stabilization occurs at 6-7 days after treatment, coinciding with macrophage infiltration into tumours ${ }^{27}$. In this case, NO production, mediated by infiltrating macrophages, was responsible. Inhibition of macrophage function or blockade of NO synthesis during and after radiation treatment 
prevented upregulation of HIF1a and prolonged growth delay after radiation treatment. The specific target of NO in this case was a single cysteine residue in the ODD of HIF1, which prevented HIF from being recognized by the VHl complex (FIG. 1).

\section{Conclusion}

It is important to note that HIF1 has complex effects on tumour cell biology and these effects might have a role in optimizing strategies for HIF1 inhibition when combined with radiation or chemotherapy. On one hand, blockade of HIF1 activity severely compromises the ability of tumour cells to undergo anaerobic glycolysis ${ }^{138}$. This will reduce the proliferation rate of hypoxic cells and promote necrosis or apoptosis in cells that are deprived of both oxygen and glucose. This effect is attractive, as it provides a clear mechanism for killing relatively radioresistant and chemoresistant hypoxic cells. On the other hand, cells that contain wild-type p53 are more prone to undergo apoptotic death after radiation if the HIF1 response is intact ${ }^{138}$. Anti-tumour effects of HIF1 inhibition may be preserved in such cases if HIF1 inhibition is initiated after cytotoxic therapy. Alternatively, it has recently been reported that inhibition of angiogenesis can lead to tumour cell apoptosis when combined with ${ }^{131}$ I radiotherapy in a tumour line that does not contain a functional p53 (REF. 141).

The response of HIF1 to cytotoxic therapy appears to be predicated on the presence of hypoxia before treatment. Both stress granules and free radical species are important in stabilizing HIF1a and hence induce HIF1-mediated gene expression after treatment, potentially reducing the sensitivity to such agents. The upregulation of HIF1 activity in this setting promotes endothelial cell survival, while creating pleiotropic effects on tumour cells that counterbalance promotion of apoptosis versus cell survival. The axis can be tipped toward cell death by judicious scheduling of HIF1 inhibition with radiotherapy or by using anti-angiogenic therapies in combination with radiotherapy (FIG. 5).

\section{Supplementary Material}

Refer to Web version on PubMed Central for supplementary material.

\section{Acknowledgments}

The authors acknowledge the helpful discussions with I. Cardenas-Navia, T. Schroeder, E. Moon and A. Manzoor in the preparation of this manuscript. B. Sorg's contributions to the laboratory form important bases for the concepts presented. Two decades of collaboration with T. Secomb led to many of the insights provided in this Review. The authors also acknowledge the support of I. Fridovich, B. Haberle and Z. Vujaskovic for introducing them to SOD mimetics that were used to test important hypotheses regarding the role of reactive oxygen species in HIF1a regulation and angiogenesis. Supported by grants from the NIH CA40355 and the Duke SPORE for Breast Cancer.

\section{Glossary}

Microangiography This method permits visualization of microvessels in a tissue following injection of an X-ray contrast agent and exposure to X-rays; X-ray film or digital imaging are used to visualize the vessels.

Vascular casting With this method, a cast of microvessels as they actually exist in tissues is preserved to permit visualization. Vasculature is filled with a polymer that sets inside the vessels. The tissue is then digested away to leave just the cast of the microvessels.

\section{At a glance}


- This Review discusses four important and interrelated features of tumour hypoxia: the hypoxic response, the factors that influence tumour hypoxia, the role of hypoxia in the initiation of angiogenesis (angiogenic switch) and how hypoxia influences treatment responses.

- The hypoxia response, driven primarily by the heterodimeric transcription factor hypoxia-inducible factor 1 (HIF1) influences cell survival, behaviour and angiogenesis.

- Several pathophysiological factors contribute to the development of tumour hypoxia, which is typified by heterogeneity in oxygenation in space and in time.

- Conflicting theories exist with respect to whether hypoxic stabilization of HIF1 is the primary feature of the angiogenic switch. There is clear evidence that HIF1 upregulation is associated with angiogenesis acceleration as opposed to angiogenesis initiation.

- The appearance of perivascular (oxygenated regions) HIF1 expression during angiogenesis acceleration might be the result of increased levels of reactive oxygen species, associated with proliferation and/or instability in flow and hypoxiareoxygenation injury.

- Cytotoxic therapies, such as radiation therapy, improve tumour oxygenation but also increase HIF1 levels and transactivation of target genes through mechanisms associated with stress granule depolymerization and the production of free radicals. The upregulation of HIF1 in these circumstances protects tumour and endothelial cells from damage by the cytotoxic therapy.

Shunt vessels These are large-diameter vessels that directly connect between feeding and draining vessels at the periphery of a tumour. These can shunt flow around the main body of the tumour, thereby starving the tumour of nutrients.

Redox ratio This ratio, which is derived from the relative abundance of two naturally fluorescent coenzymes, fAD and NADH, is related to the metabolic activity of a tissue.

Hypoxic cytotoxin Hypoxic cytotoxins are drugs that are selectively toxic to hypoxic cells.

Laser Doppler flowmetry This method measures velocity of red blood cells in tissue. When a laser illuminates tissue the light strikes red blood cells that are moving. The reflected light undergoes a detectable change in shift in frequency (Doppler shift) that is related to red blood cell velocity.

Blood oxygen level detection magnetic resonance imaging (BOLD MRI.) This is an MRI method that is sensitive to the difference in magnetic properties of deoxyhaemoglobin versus oxyhaemoglobin.

Dynamic contrast enhanced MRI (DCe MRI.) This is a method to measure perfusion/ permeability of an MR contrast agent as it enters and leaves a tissue following bolus intravenous injection. Kinetic analysis permits derivation of parameters related to vascular permeability and perfusion.

Vasomotion Arterioles in the peripheral circulation exhibit fluctuations in diameter that control perfusion of dependent tissues.

Bifurcation point This term refers to a branch point in the microcirculation, in which flow splits from one vessel to two or more daughter vessels. 
Carotid body The carotid body is a collection of $\mathrm{pH}-$, partial pressure of $\mathrm{O}_{2}\left(\mathrm{pO}_{2}\right)$ - and $\mathrm{pCO}_{2}$-sensitive chemoreceptor cells located on the carotid artery wall. When stimulated they send signals to the central nervous system to regulate respiratory and heart rates.

Dormancy This is a state of tumour growth at a time when cell loss is equal to cell proliferation and before the onset of angiogenesis.

Stress granules Cell stress initiators, such as nutritional deprivation or hypoxia, cause a general downregulation of protein translation, involving prevention of mRNA entry into ribosomes, forming stress granules (in complex with RNA-binding proteins) in the cytoplasm. Stress granules rapidly disaggregate upon removal of stress, permitting subsequent protein translation.

\section{References}

1. Virchow, R. Die Krankhaften Geschwulste. Hirschwald; Berlin: Aug. 1863 [The first report that vascular structures in tumours are abnormal.]

2. Goldman E. Growth of malignant disease in man and the lower animals with special reference to vascular system. Proc. R. Soc. Med. 1907; 1:1.

3. Warren, BA. Tumor Blood Circulation: Angiogenesis, vascular morphology and blood flow of experimental and human tumors. Peterson, HI., editor. CRC Press; Boca Raton: 1979. p. 1-48.

4. Folkman J. Tumor angiogenesis: therapeutic implications. N. Engl. J. Med. 1971; 285:1182-1186. [PubMed: 4938153] [The first to suggest that inhibition of tumour angiogenesis could have therapeutic benefit.]

5. Vaupel P, Thews O, Kelleher DK, Hoeckel M. Oxygenation of human tumors: the Mainz experience. Strahlenther. Onkol. 1998; 174(Suppl. 4):6-12. [PubMed: 9879340]

6. Braun RD, Lanzen JL, Snyder SA, Dewhirst MW. Comparison of tumor and normal tissue oxygen tension measurements using OxyLite or microelectrodes in rodents. Am. J. Physiol. Heart Circ. Physiol. 2001; 280:H2533-H2544. [PubMed: 11356608]

7. Semenza GL. Targeting HIF-1 for cancer therapy. Nature Rev. Cancer. 2003; 3:721-732. [PubMed: 13130303]

8. Wang GL, Semenza GL. General involvement of hypoxia-inducible factor 1 in transcriptional response to hypoxia. Proc. Natl Acad. Sci. USA. 1993; 90:4304-4308. [PubMed: 8387214]

9. Semenza GL, Wang GL. A nuclear factor induced by hypoxia via de novo protein synthesis binds to the human erythropoietin gene enhancer at a site required for transcriptional activation. Mol. Cell. Biol. 1992; 12:5447-5454. [PubMed: 1448077] [Discovered that HIF1 is the oxygen-sensitive transcription factor that controls erythropoeitin synthesis.]

10. Jaakkola $\mathrm{P}$, et al. Targeting of HIF-a to the von Hippel-Lindau ubiquitylation complex by $\mathrm{O}_{2-}$ regulated prolyl hydroxylation. Science. 2001; 292:468-472. [PubMed: 11292861] [The first to report that prolyl hydroxylation, which requires molecular oxygen, is the fundamental mechanism for stabilizing HIF1a under hypoxic conditions..]

11. Ohh M, et al. Ubiquitination of hypoxia-inducible factor requires direct binding to the beta-domain of the von Hippel-Lindau protein. Nature Cell Biol. 2000; 2:423-427. [PubMed: 10878807] [The first to report that oxygen-dependent degradation of HIF1a occurs by recognition of the protein by the VHL complex.]

12. Thurman RG, Ji S, Matsumura T, Lemasters JJ. Is hypoxia involved in the mechanism of alcoholinduced liver injury? Fundam. Appl. Toxicol. 1984; 4:125-133. [PubMed: 6724187]

13. Wangsa-Wirawan ND, Linsenmeier RA. Retinal oxygen: fundamental and clinical aspects. Arch Ophthalmol. 2003; 121:547-557. [PubMed: 12695252]

14. Haroon ZA, Raleigh JA, Greenberg CS, Dewhirst MW. Early wound healing exhibits cytokine surge without evidence of hypoxia. Ann. Surg. 2000; 231:137-147. [PubMed: 10636114]

15. Hale LP, Braun RD, Gwinn WM, Greer PK, Dewhirst MW. Hypoxia in the thymus: role of oxygen tension in thymocyte survival. Am. J. Physiol. Heart. Circ. Physiol. 2002; 282:H1467-1477. [PubMed: 11893584] 
16. Samoszuk MK, Walter J, Mechetner E. Improved immunohistochemical method for detecting hypoxia gradients in mouse tissues and tumors. J. Histochem. Cytochem. 2004; 52:837-839. [PubMed: 15150293]

17. Henquell L, Odoroff CL, Honig CR. Coronary intercapillary distance during growth: relation to $\mathrm{PtO}_{2}$ and aerobic capacity. Am J. Physiol. 1976; 231:1852-1859. [PubMed: 990126]

18. Parmar K, Mauch P, Vergilio JA, Sackstein R, Down JD. Distribution of hematopoietic stem cells in the bone marrow according to regional hypoxia. Proc. Natl Acad. Sci. USA. 2007; 104:54315436. [PubMed: 17374716]

19. Arteel GE, Thurman RG, Yates JM, Raleigh JA. Evidence that hypoxia markers detect oxygen gradients in liver: pimonidazole and retrograde perfusion of rat liver. Br. J. Cancer. 1995; 72:889895. [PubMed: 7547236]

20. Laughlin KM, et al. Biodistribution of the nitroimidazole EF5 (2-[2-nitro-1H-imidazol-1-yl]-N-(2, 2, 3, 3, 3-pentafluoropropyl) acetamide) in mice bearing subcutaneous EMT6 tumors. J. Pharmacol. Exp. Ther. 1996; 277:1049-1057. [PubMed: 8627516]

21. Rosmorduc $\mathrm{O}$, et al. Hepatocellular hypoxia-induced vascular endothelial growth factor expression and angiogenesis in experimental biliary cirrhosis. Am. J. Pathol. 1999; 155:1065-1073. [PubMed: 10514389]

22. Houck KA, Leung DW, Rowland AM, Winer J, Ferrara N. Dual regulation of vascular endothelial growth factor bioavailability by genetic and proteolytic mechanisms. J. Biol. Chem. 1992; 267:26031-26037. [PubMed: 1464614]

23. Fannon M, et al. Binding inhibition of angiogenic factors by heparan sulfate proteoglycans in aqueous humor: potential mechanism for maintenance of an avascular environment. FASEB J. 2003; 17:902-904. [PubMed: 12626427]

24. Chou SC, Azuma Y, Varia MA, Raleigh JA. Evidence that involucrin, a marker for differentiation, is oxygen regulated in human squamous cell carcinomas. Br. J. Cancer. 2004; 90:728-735. [PubMed: 14760391]

25. Zhu Y, et al. Hypoxia upregulates osteopontin expression in NIH-3T3 cells via a Ras-activated enhancer. Oncogene. 2005; 24:6555-6563. [PubMed: 16007184]

26. Huang JH, et al. Requirements for T lymphocyte migration in explanted lymph nodes. J. Immunol. 2007; 178:7747-7755. [PubMed: 17548612]

27. Li F, et al. Regulation of HIF-1a stability through S-nitrosylation. Mol. Cell. 2007; 26:63-74. [PubMed: 17434127] [This paper proved that nitrosylation of a cysteine residue in the oxygendependent degradation domain of HIF1a can prevent its degradation under aerobic conditions.]

28. Chandel NS, et al. Reactive oxygen species generated at mitochondrial complex III stabilize hypoxia-inducible factor-1a during hypoxia: a mechanism of $\mathrm{O}_{2}$ sensing. J. Biol. Chem. 2000; 275:25130-25138. [PubMed: 10833514] [The first report suggesting that reactive oxygen species may be responsible for stabilizing HIF1a under hypoxic conditions..]

29. Guzy RD, et al. Mitochondrial complex III is required for hypoxia-induced ROS production and cellular oxygen sensing. Cell Metab. 2005; 1:401-408. [PubMed: 16054089]

30. Bell EL, et al. The Qo site of the mitochondrial complex III is required for the transduction of hypoxic signaling via reactive oxygen species production. J. Cell Biol. 2007; 177:1029-1036. [PubMed: 17562787]

31. Ignarro LJ. Nitric oxide as a unique signaling molecule in the vascular system: a historical overview. J. Physiol. Pharmacol. 2002; 53:503-514. [PubMed: 12512688]

32. Pryor WA, et al. Free radical biology and medicine: it's a gas, man! Am. J. Physiol. Regul. Integr. Comp. Physiol. 2006; 291:R491-511. [PubMed: 16627692]

33. Moncada S, Higgs EA. The discovery of nitric oxide and its role in vascular biology. Br. J. Pharmacol. 2006; 147(Suppl. 1):S193-S201. [PubMed: 16402104]

34. Tozer GM, Everett SA. Nitric oxide in tumor biology and cancer therapy. Part 2: Therapeutic implications. Clin. Oncol. (R. Coll. Radiol.). 1997; 9:357-364.

35. Tozer GM, Everett SA. Nitric oxide in tumour biology and cancer therapy. Part 1: Physiological aspects. Clin. Oncol. (R. Coll. Radiol.). 1997; 9:282-293. [PubMed: 9368723]

36. BelAiba RS, et al. Redox-sensitive regulation of the HIF pathway under non-hypoxic conditions in pulmonary artery smooth muscle cells. Biol. Chem. 2004; 385:249-257. [PubMed: 15134338] 
37. Page EL, Chan DA, Giaccia AJ, Levine M, Richard DE. Hypoxia-inducible factor-1a stabilization in nonhypoxic conditions: role of oxidation and intracellular ascorbate depletion. Mol. Biol. Cell. 2008; 19:86-94. [PubMed: 17942596]

38. Mateo J, Garcia-Lecea M, Cadenas S, Hernandez C, Moncada S. Regulation of hypoxia-inducible factor-1a by nitric oxide through mitochondria-dependent and -independent pathways. Biochem. J. 2003; 376:537-544. [PubMed: 14531732]

39. Sumbayev VV, Budde A, Zhou J, Brune B. HIF-1 a protein as a target for S-nitrosation. FEBS Lett. 2003; 535:106-112. [PubMed: 12560087]

40. Kimura $\mathrm{H}$, et al. Identification of hypoxia-inducible factor 1 ancillary sequence and its function in vascular endothelial growth factor gene induction by hypoxia and nitric oxide. J. Biol. Chem. 2001; 276:2292-2298. [PubMed: 11056166]

41. Sandau KB, Faus HG, Brune B. Induction of hypoxia-inducible-factor 1 by nitric oxide is mediated via the PI 3K pathway. Biochem. Biophys. Res. Commun. 2000; 278:263-267. [PubMed: 11071882]

42. Kasuno K, et al. Nitric oxide induces hypoxiainducible factor 1 activation that is dependent on MAPK and phosphatidylinositol 3-kinase signaling. J. Biol. Chem. 2004; 279:2550-2558. [PubMed: 14600153]

43. Mansfield KD, et al. Mitochondrial dysfunction resulting from loss of cytochrome c impairs cellular oxygen sensing and hypoxic HIF-a activation. Cell Metab. 2005; 1:393-399. [PubMed: 16054088]

44. Venkataraman S, et al. Manganese superoxide dismutase overexpression inhibits the growth of androgen-independent prostate cancer cells. Oncogene. 2005; 24:77-89. [PubMed: 15543233]

45. Wang M, et al. Manganese superoxide dismutase suppresses hypoxic induction of hypoxiainducible factor-1a and vascular endothelial growth factor. Oncogene. 2005; 24:8154-8166. [PubMed: 16170370]

46. Liu Y, et al. Carbon monoxide and nitric oxide suppress the hypoxic induction of vascular endothelial growth factor gene via the $5^{\prime}$ enhancer. J. Biol. Chem. 1998; 273:15257-15262. [PubMed: 9614141]

47. Huang LE, Willmore WG, Gu J, Goldberg MA, Bunn HF. Inhibition of hypoxia-inducible factor 1 activation by carbon monoxide and nitric oxide. Implications for oxygen sensing and signaling. J. Biol. Chem. 1999; 274:9038-9044. [PubMed: 10085152]

48. Hagen T, Taylor CT, Lam F, Moncada S. Redistribution of intracellular oxygen in hypoxia by nitric oxide: effect on HIF1a. Science. 2003; 302:1975-1978. [PubMed: 14671307]

49. Berchner-Pfannschmidt U, Yamac H, Trinidad B, Fandrey J. Nitric oxide modulates oxygen sensing by hypoxia-inducible factor 1-dependent induction of prolyl hydroxylase 2. J. Biol. Chem. 2007; 282:1788-1796. [PubMed: 17060326]

50. Jankovic B, et al. Comparison between pimonidazole binding, oxygen electrode measurements, and expression of endogenous hypoxia markers in cancer of the uterine cervix. Cytometry B Clin. Cytom. 2006; 70:45-55. [PubMed: 16456867]

51. Raleigh JA, et al. Hypoxia and vascular endothelial growth factor expression in human squamous cell carcinomas using pimonidazole as a hypoxia marker. Cancer Res. 1998; 58:3765-3768. [PubMed: 9731480]

52. Vordermark D, Brown JM. Evaluation of hypoxiainducible factor-1a (HIF-1a) as an intrinsic marker of tumor hypoxia in U87 MG human glioblastoma: in vitro and xenograft studies. Int. J. Radiat. Oncol. Biol. Phys. 2003; 56:1184-1193. [PubMed: 12829158]

53. Janssen HL, et al. HIF-1A, pimonidazole, and iododeoxyuridine to estimate hypoxia and perfusion in human head-and-neck tumors. Int. J. Radiat. Oncol. Biol. Phys. 2002; 54:1537-1549. [PubMed: 12459383]

54. Quintero M, Brennan PA, Thomas GJ, Moncada S. Nitric oxide is a factor in the stabilization of hypoxia-inducible factor-1a in cancer: role of free radical formation. Cancer Res. 2006; 66:770 774. [PubMed: 16424008]

55. Brown JM, Wilson WR. Exploiting tumour hypoxia in cancer treatment. Nature Rev. Cancer. 2004; 4:437-447. [PubMed: 15170446] 
56. Ljungkvist AS, Bussink J, Kaanders JH, van der Kogel AJ. Dynamics of tumor hypoxia measured with bioreductive hypoxic cell markers. Radiat. Res. 2007; 167:127-145. [PubMed: 17390721]

57. Vaupel P, Harrison L. Tumor hypoxia: causative factors, compensatory mechanisms, and cellular response. Oncologist. 2004; 9(Suppl. 5):4-9. [PubMed: 15591417]

58. Dewhirst MW, et al. Quantification of longitudinal tissue $\mathrm{pO}_{2}$ gradients in window chamber tumours: impact on tumour hypoxia. Br. J. Cancer. 1999; 79:1717-1722. [PubMed: 10206282]

59. Secomb TW, Hsu R, Dewhirst MW, Klitzman B, Gross JF. Analysis of oxygen transport to tumor tissue by microvascular networks. Int. J. Radiat. Oncol. Biol. Phys. 1993; 25:481-489. [PubMed: 8436527]

60. Secomb TW, Hsu R, Park EY, Dewhirst MW. Green's function methods for analysis of oxygen delivery to tissue by microvascular networks. Ann. Biomed. Eng. 2004; 32:1519-1529. [PubMed: 15636112]

61. Dewhirst MW, et al. Microvascular studies on the origins of perfusion-limited hypoxia. Br. J. Cancer Suppl. 1996; 27:S247-251. [PubMed: 8763890] [The first report to demonstrate that arteriolar vasomotion can be involved in intermittent hypoxia.]

62. Erickson K, et al. Effect of longitudinal oxygen gradients on effectiveness of manipulation of tumor oxygenation. Cancer Res. 2003; 63:4705-4712. [PubMed: 12907653]

63. Sorg BS, Moeller BJ, Donovan O, Cao Y, Dewhirst MW. Hyperspectral imaging of hemoglobin saturation in tumor microvasculature and tumor hypoxia development. J. Biomed. Opt. 2005; 10:44004. [PubMed: 16178638]

64. Ljungkvist AS, et al. Vascular architecture, hypoxia, and proliferation in first-generation xenografts of human head-and-neck squamous cell carcinomas. Int. J. Radiat. Oncol. Biol. Phys. 2002; 54:215-228. [PubMed: 12182995]

65. Devasahayam N, et al. Strategies for improved temporal and spectral resolution in in vivo oximetric imaging using time-domain EPR. Magn. Reson. Med. 2007; 57:776-783. [PubMed: 17390350]

66. Wijffels KI, et al. Vascular architecture and hypoxic profiles in human head and neck squamous cell carcinomas. Br. J. Cancer. 2000; 83:674-683. [PubMed: 10944611]

67. Brown JM. Evidence for acutely hypoxic cells in mouse tumours, and a possible mechanism of reoxygenation. Br. J. Radiol. 1979; 52:650-656. [PubMed: 486895] [The first report that intermittent hypoxia that is radiobiologically important can be found in tumours.]

68. Reinhold HS, Blachiwiecz B, Blok A. Oxygenation and reoxygenation in 'sandwich' tumours. Bibl. Anat. 1977:270-272. [PubMed: 597154]

69. Yamaura H, Matsuzawa T. Tumor regrowth after irradiation; an experimental approach. Int. J. Radiat. Biol. Relat. Stud. Phys. Chem. Med. 1979; 35:201-219. [PubMed: 222702]

70. Dewhirst MW. Intermittent hypoxia furthers the rationale for hypoxia-inducible factor-1 targeting. Cancer Res. 2007; 67:854-855. [PubMed: 17283112]

71. Durand RE, Aquino-Parsons C. Clinical relevance of intermittent tumour blood flow. Acta Oncol. 2001; 40:929-936. [PubMed: 11845957]

72. Chaplin DJ, Olive PL, Durand RE. Intermittent blood flow in a murine tumor: radiobiological effects. Cancer Res. 1987; 47:597-601. [PubMed: 3791244]

73. Chaplin DJ, Trotter MJ, Durand RE, Olive PL, Minchinton AI. Evidence for intermittent radiobiological hypoxia in experimental tumour systems. Biomed. Biochim. Acta. 1989; 48:S255259. [PubMed: 2730619]

74. Minchinton AI, Durand RE, Chaplin DJ. Intermittent blood flow in the KHT sarcoma - flow cytometry studies using Hoechst 33342. Br. J. Cancer. 1990; 62:195-200. [PubMed: 2386734]

75. Thomas CD, Stern S, Chaplin DJ, Guichard M. Transient perfusion and radiosensitizing effect after nicotinamide, carbogen, and perflubron emulsion administration. Radiother. Oncol. 1996; 39:235-241. [PubMed: 8783400]

76. Trotter MJ, Chaplin DJ, Olive PL. Effect of angiotensin II on intermittent tumour blood flow and acute hypoxia in the murine SCCVII carcinoma. Eur. J. Cancer. 1991; 27:887-893. [PubMed: 1834122]

77. Chaplin DJ, Durand RE, Olive PL. Acute hypoxia in tumors: implications for modifiers of radiation effects. Int. J. Radiat. Oncol. Biol. Phys. 1986; 12:1279-1282. [PubMed: 3759546] 
78. Durand RE. Intermittent blood flow in solid tumours — an under-appreciated source of 'drug resistance'. Cancer Metastasis Rev. 2001; 20:57-61. [PubMed: 11831648]

79. Durand RE, Aquino-Parsons C. Non-constant tumour blood flow — implications for therapy. Acta Oncol. 2001; 40:862-869. [PubMed: 11859987]

80. Kimura H, et al. Fluctuations in red cell flux in tumor microvessels can lead to transient hypoxia and reoxygenation in tumor parenchyma. Cancer Res. 1996; 56:5522-5528. [PubMed: 8968110] [The first report to show that intermittent hypoxia can be caused by instabilities in tumour microvessel red cell flux and that vascular stasis is not required for this effect.]

81. Lanzen J, et al. Direct demonstration of instabilities in oxygen concentrations within the extravascular compartment of an experimental tumor. Cancer Res. 2006; 66:2219-2223. [PubMed: 16489024]

82. Braun RD, Lanzen JL, Dewhirst MW. Fourier analysis of fluctuations of oxygen tension and blood flow in R3230Ac tumors and muscle in rats. Am. J. Physiol. 1999; 277:H551-568. [PubMed: 10444480]

83. Brurberg KG, Skogmo HK, Graff BA, Olsen DR, Rofstad EK. Fluctuations in $\mathrm{pO}_{2}$ in poorly and well-oxygenated spontaneous canine tumors before and during fractionated radiation therapy. Radiother. Oncol. 2005; 77:220-226. [PubMed: 16257074] [The first report that intermittent hypoxia can occur in clinically-relevant canine tumours..]

84. Cardenas-Navia LI, et al. Tumor-dependent kinetics of partial pressure of oxygen fluctuations during air and oxygen breathing. Cancer Res. 2004; 64:6010-6017. [PubMed: 15342381]

85. Pigott KH, Hill SA, Chaplin DJ, Saunders MI. Microregional fluctuations in perfusion within human tumours detected using laser Doppler flowmetry. Radiother. Oncol. 1996; 40:45-50. [PubMed: 8844886]

86. Bennewith KL, Raleigh JA, Durand RE. Orally administered pimonidazole to label hypoxic tumor cells. Cancer Res. 2002; 62:6827-6830. [PubMed: 12460894]

87. Cardenas-Navia LI, et al. The pervasive presence of fluctuating oxygenation in tumors. Cancer Res. (in the press).

88. Sorg BS, Hardee ME, Agarwal N, Moeller BJ, Dewhirst MW. Spectral imaging facilitates visualization and measurements of unstable and abnormal microvascular oxygen transport in tumors. J. Biomed. Opt. 2008; 13:014026. [PubMed: 18315384]

89. Baudelet $\mathrm{C}$, et al. Physiological noise in murine solid tumours using T2*-weighted gradient-echo imaging: a marker of tumour acute hypoxia? Phys. Med. Biol. 2004; 49:3389-3411. [PubMed: 15379021]

90. Brurberg KG, Benjaminsen IC, Dorum LM, Rofstad EK. Fluctuations in tumor blood perfusion assessed by dynamic contrast-enhanced MRI. Magn. Reson. Med. 2007; 58:473-481. [PubMed: 17763357]

91. Baudelet $\mathrm{C}$, et al. The role of vessel maturation and vessel functionality in spontaneous fluctuations of T2*-weighted GRE signal within tumors. NMR Biomed. 2006; 19:69-76. [PubMed: 16411170]

92. Patan S, Munn LL, Jain RK. Intussusceptive microvascular growth in a human colon adenocarcinoma xenograft: a novel mechanism of tumor angiogenesis. Microvasc. Res. 1996; 51:260-272. [PubMed: 8778579] [This paper is the first to connect the concept of vascular remodelling as a putative mechanism for intermittent hypoxia.]

93. Chien, S.; Usami, S.; Skalak, R. Handbook of Physiology. Renkin, EM.; Michel, C.; Geiger, SR., editors. American Physiological Society; Bethesda: 1984. p. 217-251.

94. Kiani MF, Pries AR, Hsu LL, Sarelius IH, Cokelet GR. Fluctuations in microvascular blood flow parameters caused by hemodynamic mechanisms. Am. J. Physiol. 1994; 266:H1822-H1828. [PubMed: 8203581]

95. Pries AR, Schonfeld D, Gaehtgens P, Kiani MF, Cokelet GR. Diameter variability and microvascular flow resistance. Am. J. Physiol. 1997; 272:H2716-H2725.

96. Kavanagh BD, Coffey BE, Needham D, Hochmuth RM, Dewhirst MW. The effect of flunarizine on erythrocyte suspension viscosity under conditions of extreme hypoxia, low $\mathrm{pH}$, and lactate treatment. Br. J. Cancer. 1993; 67:734-741. [PubMed: 8471430]

97. Cao Y, et al. Observation of incipient tumor angiogenesis that is independent of hypoxia and hypoxia inducible factor-1 activation. Cancer Res. 2005; 65:5498-5505. [PubMed: 15994919] 
[This paper provides evidence in a preclinical model that hypoxia is not a prerequisite for the initiation of tumour angiogenesis.]

98. Nehmeh SA, et al. Reproducibility of intratumor distribution of 18F-fluoromisonidazole in head and neck cancer. Int. J. Radiat. Oncol. Biol. Phys. 2008; 70:235-242. [PubMed: 18086391]

99. Peng YJ, et al. Heterozygous HIF-1a deficiency impairs carotid body-mediated systemic responses and reactive oxygen species generation in mice exposed to intermittent hypoxia. J. Physiol. 2006; 577:705-716. [PubMed: 16973705]

100. Yuan G, Nanduri J, Bhasker CR, Semenza GL, Prabhakar NR. $\mathrm{Ca}^{2+} /$ calmodulin kinasedependent activation of hypoxia inducible factor 1 transcriptional activity in cells subjected to intermittent hypoxia. J. Biol. Chem. 2005; 280:4321-4328. [PubMed: 15569687]

101. Semenza GL, Prabhakar NR. HIF-1-dependent respiratory, cardiovascular, and redox responses to chronic intermittent hypoxia. Antioxid. Redox Signal. 2007; 9:1391-1396. [PubMed: 17627473]

102. Toffoli S, Feron O, Raes M, Michiels C. Intermittent hypoxia changes HIF-1a phosphorylation pattern in endothelial cells: unravelling of a new PKA-dependent regulation of HIF-1a. Biochim. Biophys. Acta. 2007; 1773:1558-1571. [PubMed: 17662481]

103. Martinive $P$, et al. Preconditioning of the tumor vasculature and tumor cells by intermittent hypoxia: implications for anticancer therapies. Cancer Res. 2006; 66:11736-11744. [PubMed: 17178869] [This report shows that HIF1 upregulation is more strongly induced by repeated exposures to hypoxia-reoxygenation than by chronic hypoxia.]

104. Sioussat TM, Dvorak HF, Brock TA, Senger DR. Inhibition of vascular permeability factor (vascular endothelial growth factor) with antipeptide antibodies. Arch. Biochem. Biophys. 1993; 301:15-20. [PubMed: 8442657]

105. Senger DR, Perruzzi CA, Feder J, Dvorak HF. A highly conserved vascular permeability factor secreted by a variety of human and rodent tumor cell lines. Cancer Res. 1986; 46:5629-5632. [PubMed: 3756910]

106. Ferrara N, Henzel WJ. Pituitary follicular cells secrete a novel heparin-binding growth factor specific for vascular endothelial cells. Biochem. Biophys. Res. Commun. 1989; 161:851-858. [PubMed: 2735925] [This is the first report that VEGF is a mitogen for endothelial cells.]

107. Leung DW, Cachianes G, Kuang WJ, Goeddel DV, Ferrara N. Vascular endothelial growth factor is a secreted angiogenic mitogen. Science. 1989; 246:1306-1309. [PubMed: 2479986]

108. Yuan F, et al. Time-dependent vascular regression and permeability changes in established human tumor xenografts induced by an anti-vascular endothelial growth factor/vascular permeability factor antibody. Proc. Natl Acad. Sci. USA. 1996; 93:14765-14770. [PubMed: 8962129]

109. Holash J, et al. Vessel cooption, regression, and growth in tumors mediated by angiopoietins and VEGF. Science. 1999; 284:1994-1998. [PubMed: 10373119] [This report is the first to theorize that a hypoxic crisis, mediated by regression of coopted host microvasculature, may be required for tumour angiogenesis initiation.]

110. Holash J, Wiegand SJ, Yancopoulos GD. New model of tumor angiogenesis: dynamic balance between vessel regression and growth mediated by angiopoietins and VEGF. Oncogene. 1999; 18:5356-5362. [PubMed: 10498889]

111. Lin $\mathrm{P}$, et al. Inhibition of tumor angiogenesis using a soluble receptor establishes a role for Tie2 in pathologic vascular growth. J. Clin. Invest. 1997; 100:2072-2078. [PubMed: 9329972] [This is the first paper demonstrating the importance of TIE2, the receptor for angiopoietins, as a proangiogenic endothelial cell receptor in tumours.]

112. Peters KG, et al. Functional significance of Tie2 signaling in the adult vasculature. Recent Prog. Horm. Res. 2004; 59:51-71. [PubMed: 14749497]

113. Winkles JA, et al. Human vascular smooth muscle cells both express and respond to heparinbinding growth factor I (endothelial cell growth factor). Proc. Natl Acad. Sci. USA. 1987; 84:7124-7128. [PubMed: 2444975]

114. Soker S, Takashima S, Miao HQ, Neufeld G, Klagsbrun M. Neuropilin-1 is expressed by endothelial and tumor cells as an isoform-specific receptor for vascular endothelial growth factor. Cell. 1998; 92:735-745. [PubMed: 9529250] 
115. Mazure NM, Chen EY, Yeh P, Laderoute KR, Giaccia AJ. Oncogenic transformation and hypoxia synergistically act to modulate vascular endothelial growth factor expression. Cancer Res. 1996; 56:3436-3440. [PubMed: 8758908]

116. Diaz-Gonzalez JA, Russell J, Rouzaut A, Gil-Bazo I, Montuenga L. Targeting hypoxia and angiogenesis through HIF-1a inhibition. Cancer Biol. Ther. 2005; 4:1055-1062. [PubMed: 16294030]

117. Laderoute KR, et al. Opposing effects of hypoxia on expression of the angiogenic inhibitor thrombospondin 1 and the angiogenic inducer vascular endothelial growth factor. Clin. Cancer Res. 2000; 6:2941-2950. [PubMed: 10914744]

118. Steinman S, Wang J, Bourne P, Yang Q, Tang P. Expression of cytokeratin markers, ER-a, PR, HER-2/neu, and EGFR in pure ductal carcinoma in situ (DCIS) and DCIS with co-existing invasive ductal carcinoma (IDC) of the breast. Ann. Clin. Lab. Sci. 2007; 37:127-134. [PubMed: 17522367]

119. Dabbs DJ, Chivukula M, Carter G, Bhargava R. Basal phenotype of ductal carcinoma in situ: recognition and immunohistologic profile. Mod. Pathol. 2006; 19:1506-1511. [PubMed: 16941011]

120. Kamat CD, et al. Mutant p53 facilitates proangiogenic, hyperproliferative phenotype in response to chronic relative hypoxia. Cancer Lett. 2007; 249:209-219. [PubMed: 16997458]

121. Zhou S, et al. Frequency and phenotypic implications of mitochondrial DNA mutations in human squamous cell cancers of the head and neck. Proc. Natl Acad. Sci. USA. 2007; 104:7540-7545. [PubMed: 17456604]

122. Feldkamp MM, Lau N, Rak J, Kerbel RS, Guha A. Normoxic and hypoxic regulation of vascular endothelial growth factor (VEGF) by astrocytoma cells is mediated by Ras. Int. J. Cancer. 1999; 81:118-124. [PubMed: 10077162]

123. Jiang BH, Liu LZ. AKT signaling in regulating angiogenesis. Curr. Cancer Drug Targets. 2008; 8:19-26. [PubMed: 18288940]

124. Naumov GN, et al. A model of human tumor dormancy: an angiogenic switch from the nonangiogenic phenotype. J. Natl Cancer Inst. 2006; 98:316-325. [PubMed: 16507828]

125. Stessels F, et al. Breast adenocarcinoma liver metastases, in contrast to colorectal cancer liver metastases, display a non-angiogenic growth pattern that preserves the stroma and lacks hypoxia. Br. J. Cancer. 2004; 90:1429-1436. [PubMed: 15054467] [The first report that vessel cooption can occur in human cancer.]

126. Colpaert CG, et al. Cutaneous breast cancer deposits show distinct growth patterns with different degrees of angiogenesis, hypoxia and fibrin deposition. Histopathology. 2003; 42:530-540. [PubMed: 12786888]

127. Bos R, et al. Levels of hypoxia-inducible factor-1 a during breast carcinogenesis. J. Natl Cancer Inst. 2001; 93:309-314. [PubMed: 11181778]

128. Zakrzewicz A, Secomb TW, Pries AR. Angioadaptation: keeping the vascular system in shape. News Physiol. Sci. 2002; 17:197-201. [PubMed: 12270956]

129. Gregoire V, Hittelman WN, Rosier JF, Milas L. Chemo-radiotherapy: radiosensitizing nucleoside analogues (review). Oncol. Rep. 1999; 6:949-957. [PubMed: 10425285]

130. Bussink J, Kaanders JH, Rijken PF, Raleigh JA, van der Kogel AJ. Changes in blood perfusion and hypoxia after irradiation of a human squamous cell carcinoma xenograft tumor line. Radiat. Res. 2000; 153:398-404. [PubMed: 10760999]

131. Milas L, Milross CG, Mason KA. Cytotoxic treatments and tumor oxygenation. Cancer J. Sci. Am. 1996; 2:59-60. author reply 60-61. [PubMed: 9166500]

132. Milas L, et al. Role of reoxygenation in induction of enhancement of tumor radioresponse by paclitaxel. Cancer Res. 1995; 55:3564-3568. [PubMed: 7627965]

133. Milas L, Hunter N, Mason KA, Milross C, Peters LJ. Tumor reoxygenation as a mechanism of taxol-induced enhancement of tumor radioresponse. Acta Oncol. 1995; 34:409-412. [PubMed: 7779432]

134. Rubin P, Casarett G. Microcirculation of tumors. II. The supervascularized state of irradiated regressing tumors. Clin. Radiol. 1966; 17:346-355. [PubMed: 5924244] [This paper was the first 
to suggest that radiation therapy induced a change in tumour vascular density that would favour increased oxygenation.]

135. Dewhirst MW, et al. Heterogeneity in tumor microvascular response to radiation. Int. J. Radiat. Oncol. Biol. Phys. 1990; 18:559-568. [PubMed: 2318688]

136. Moeller BJ, Cao Y, Li CY, Dewhirst MW. Radiation activates HIF-1 to regulate vascular radiosensitivity in tumors: role of reoxygenation, free radicals, and stress granules. Cancer Cell. 2004; 5:429-441. [PubMed: 15144951] [This paper demonstrated that tumour reoxygenation after radiotherapy paradoxically led to an increase in HIF1 activity through mechanisms involving free radical generation and stress granule disaggregation.]

137. Moeller BJ, et al. A manganese porphyrin superoxide dismutase mimetic enhances tumor radioresponsiveness. Int. J. Radiat. Oncol. Biol. Phys. 2005; 63:545-552. [PubMed: 16168847]

138. Moeller BJ, et al. Pleiotropic effects of HIF-1 blockade on tumor radiosensitivity. Cancer Cell. 2005; 8:99-110. [PubMed: 16098463]

139. Williams KJ, et al. Enhanced response to radiotherapy in tumours deficient in the function of hypoxia-inducible factor-1. Radiother. Oncol. 2005; 75:89-98. [PubMed: 15878106]

140. Kedersha NL, Gupta M, Li W, Miller I, Anderson P. RNA-binding proteins TIA-1 and TIAR link the phosphorylation of eIF-2 a to the assembly of mammalian stress granules. J. Cell Biol. 1999; 147:1431-1442. [PubMed: 10613902]

141. Magnon C, et al. Radiation and inhibition of angiogenesis by canstatin synergize to induce HIF-1a-mediated tumor apoptotic switch. J. Clin. Invest. 2007; 117:1844-1855. [PubMed: 17557121]

142. Tatum JL, et al. Hypoxia: importance in tumor biology, noninvasive measurement by imaging, and value of its measurement in the management of cancer therapy. Int. J. Radiat. Biol. 2006; 82:699-757. [PubMed: 17118889]

143. Manzoor, AA.; Yuan, H.; Palmer, GM.; Viglianti, BL.; Dewhirst, MW. Molecular Imaging: Principles and Practice. Weissleder, R.; Gambhir, SS.; Ross, BD.; Rehemtulla, A., editors. BC Decker; Ontario: 2008.

144. Raleigh JA, Dewhirst MW, Thrall DE. Measuring tumor hypoxia. Semin. Radiat. Oncol. 1996; 6:37-45. [PubMed: 10717160]

145. Khan N, Williams BB, Hou H, Li H, Swartz HM. Repetitive tissue $\mathrm{pO}_{2}$ measurements by electron paramagnetic resonance oximetry: current status and future potential for experimental and clinical studies. Antioxid. Redox Signal. 2007; 9:1169-1182. [PubMed: 17536960]

146. Srinivasan S, et al. Developments in quantitative oxygen-saturation imaging of breast tissue in vivo using multispectral near-infrared tomography. Antioxid. Redox Signal. 2007; 9:1143-1156. [PubMed: 17627478]

147. Matsumoto K, Subramanian S, Murugesan R, Mitchell JB, Krishna MC. Spatially resolved biologic information from in vivo EPRI, OMRI, and MRI. Antioxid. Redox Signal. 2007; 9:1125-1141. [PubMed: 17571957]

148. Koch CJ. Measurement of absolute oxygen levels in cells and tissues using oxygen sensors and 2nitroimidazole EF5. Methods Enzymol. 2002; 352:3-31. [PubMed: 12125356]

149. Koch CJ, Evans SM, Lord EM. Oxygen dependence of cellular uptake of EF5 [2-(2-nitro-1Himidazol-1-yl)-N-(2, 2, 3, 3, 3-pentafluoropropyl) acetamide]: analysis of drug adducts by fluorescent antibodies vs bound radioactivity. Br. J. Cancer. 1995; 72:869-874. [PubMed: 7547233]

150. Koch CJ, Evans SM. Non-invasive PET and SPECT imaging of tissue hypoxia using isotopically labeled 2-nitroimidazoles. Adv. Exp. Med. Biol. 2003; 510:285-292. [PubMed: 12580442]

151. Padhani AR, Krohn KA, Lewis JS, Alber M. Imaging oxygenation of human tumours. Eur. Radiol. 2007; 17:861-872. [PubMed: 17043737]

152. Moon EJ, Brizel DM, Chi JT, Dewhirst MW. The potential role of intrinsic hypoxia markers as prognostic variables in cancer. Antioxid. Redox Signal. 2007; 9:1237-1294. [PubMed: 17571959]

153. Le QT, et al. Expression and prognostic significance of a panel of tissue hypoxia markers in headand-neck squamous cell carcinomas. Int. J. Radiat. Oncol. Biol. Phys. 2007; 69:167-175. [PubMed: 17707270] 
154. Vaupel P, Hockel M, Mayer A. Detection and characterization of tumor hypoxia using $\mathrm{pO}_{2}$ histography. Antioxid. Redox Signal. 2007; 9:1221-1235. [PubMed: 17536958]

155. Secomb TW, Hsu R, Ong ET, Gross JF, Dewhirst MW. Analysis of the effects of oxygen supply and demand on hypoxic fraction in tumors. Acta Oncol. 1995; 34:313-316. [PubMed: 7779415]

156. Dewhirst MW, Cao Y, Li CY, Moeller B. Exploring the role of HIF-1 in early angiogenesis and response to radiotherapy. Radiother. Oncol. 2007; 83:249-255. [PubMed: 17560674] 


\section{Box 1 | Methods to measure hypoxia}

There are a number of methods to measure hypoxia in tissues; all have advantages and disadvantages. Three key methods that are relevant to the discussions in this paper are below (for reviews see REFS 142-147).

Hypoxia marker drugs

These drugs are 2-nitroimidazoles; after entering cells they undergo 1-2 electron reduction in cells and the reduced drug is a highly reactive free radical that binds to macromolecules, including proteins ${ }^{148}$. However, when oxygen is present, the drug is oxidized and reverts back to its original state, allowing it to diffuse out of the cell and eventually into the circulation. The rate of protein binding of the reduced drug increases exponentially with a decrease in partial pressure of $\mathrm{O}_{2}$, particularly below 10 $\mathrm{mmHg}^{144,149}$. The presence of drug-protein adducts can be detected immunohistochemically using antibodies specific for the drug protein adduct. ${ }^{18} \mathrm{~F}$-labelled versions of these drugs are also being developed for positron-emission tomography imaging ${ }^{150,151}$.

Hypoxia marker proteins

As HIF1 upregulates the synthesis of many proteins, it has been proposed that identification of such proteins in tissues could be markers of hypoxia. Literally dozens of such proteins have been studied at the preclinical level and in clinical trials ${ }^{152}$. Some of the more promising endogenous markers include carbonic anhydrase IX (CA9), plasminogen activator inhibitor 1 (PAI1, also known as SERPINE), osteopontin and lysyl oxidase. Combinations of markers might prove to be better predictors of clinical outcome than any single marker ${ }^{153}$.

Oxygen electrodes and optical probes

Oxygen can be measured in any aqueous media using polarography. In principle, two electrodes are placed into the medium and a polarizing voltage of -0.7 volts is applied across them. This voltage corresponds to the binding energy of outer shell electrons of oxygen. The electrons are captured by the cathode and the current generated is linearly proportional to oxygen concentration. In practice, the cathode is embedded into a needle that can be introduced into tissues and the anode is placed on the body surface. This technique has been used extensively in preclinical and clinical studies; the presence of hypoxia is an independent predictive factor for poor prognosis in many different tumour types ${ }^{154}$. Optical probes have also been developed: these are implanted into tissues and contain a fluorochrome that emits fluorescent light with a certain decay rate when illuminated. The rate of fluorescent light decay is proportional to the oxygen concentration in the region of measurement. These probes yield data similar to that of the oxygen electrode 6 . 
Box 2 | Multiparametric imaging with the window chamber model

Window chamber models in rodents permit multiparametric analysis of tumour microcirculatory function and gene expression in the living animal. Examples of endpoints include vascular geometry, red cell flux, flow velocity, vascular permeability, leukocyte-endothelial cell interactions, tumour-endothelial cell interactions and haemoglobin saturation. Typically more than one of these parameters is measured in the same animal in the same experiment, which permits study of relationships between measured parameters. Because these measurement methods are optical and therefore noninvasive, the endpoints described can be measured repeatedly on the same animal, providing a powerful method for serially assessing the effect of therapeutic treatment or other manipulations. Shown in this example are three parameters that are particularly related to the evaluation of oxygen transport. In part a, two reporter genes are shown, which are simultaneously expressed in the same tumour cell line. Red indicates constitutively expressed red fluorescent protein. This reporter gene permits identification of all tumour cells within the field of view. Green indicates hypoxia-inducible factor 1 (HIF1)-regulated green fluorescent protein. This permits identification of tumour cells in which HIF1 is transcriptionally active. In part $\mathbf{b}$, haemoglobin saturations of tumour microvessels are imaged. Orange to red represents $70-90 \%$ saturated. Light blue represents 10-30\% saturated. Figure part $\mathbf{c}$ shows the appearance of microvessels using transillumination. Images reproduced, with permission, from REF. 156 (C) Elsevier Ireland Ltd (2007).

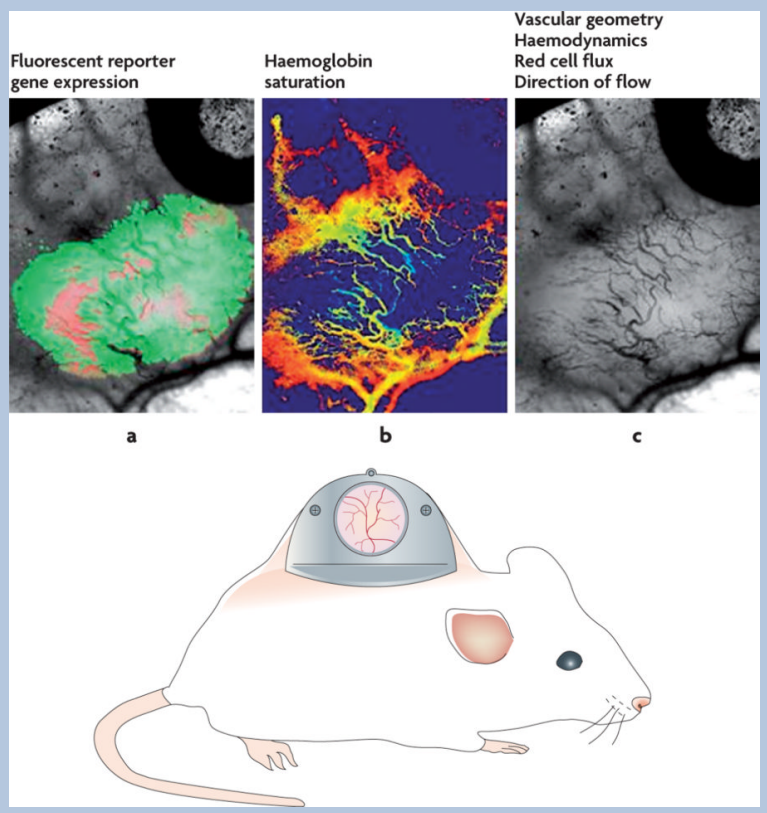




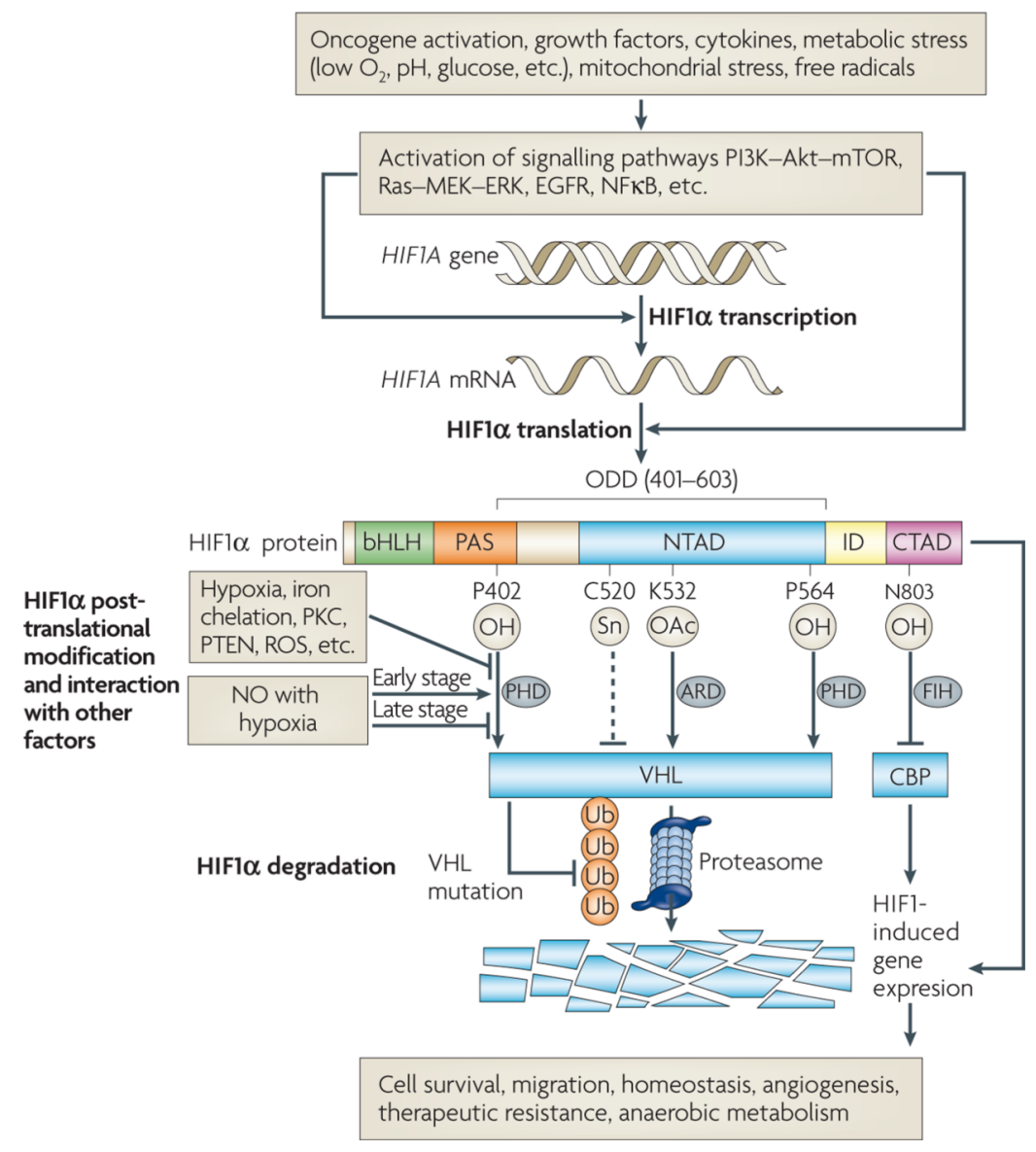

Figure 1. Features of hypoxia-inducible factor (HIF1) regulation

HIF1 transcriptional activity regulates numerous genes that control a variety of cellular functions, including anaerobic metabolism, angiogenesis stimulation and mechanisms for resistance to therapy. HIF1 transcriptional activity requires formation of a heterodimer consisting of HIF1a and HIF1 $\beta$. The heterodimer binds to hypoxia response elements (HREs) in promoter regions of its target genes, where it activates transcription. Whereas HIF $1 \beta$ is constitutively expressed, HIF1a protein levels are subject to a number of points of regulation. HIF1a consists of the following regulatory domains: bHLH (basic-helix-loophelix), PAS (Per-ARNT-Sim), NTAD (N-terminal transactivation domain), CTAD (Cterminal transactivation domain) and ODD (oxygen-dependent degradation domain). The rate of synthesis of HIF1a is controlled by activation of the phosphatidylinositol 3-kinase (PI3K)-Akt and Ras pathways by a variety of stimuli. HIF1a protein is rapidly targeted by the von Hippel-Lindau protein (VHL) complex for proteasomal degradation under normoxic conditions, following an oxygen-dependent prolyl hydroxylation of proline residues in the ODD. Activity of the prolyl hydroxylases (PHDs) is influenced by protein kinase C (PKC), PTEN and reactive oxygen species (ROS). Nitric oxide (NO) has variable effects on the stability of HIF1a, depending on the oxygenation state of the cell. Once HIF1a forms a heterodimer with its partner, HIF1 $\beta$, the transcriptional activity is further regulated by cofactors, such as CREB binding protein (CBP) or factor-inhibiting HIF (FIH). ARD, acetyl transferase. 


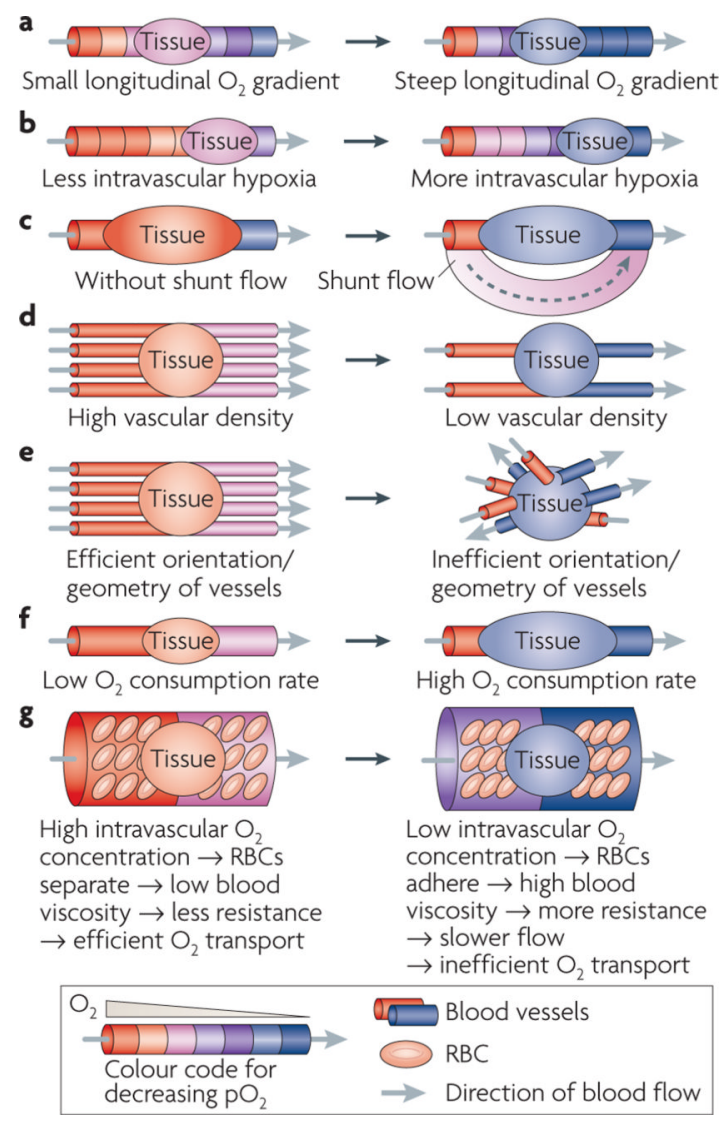

Figure 2. Seven points of regulation of tumour oxygenation

Seven features are often present in tumours, contributing in a multifactorial and interrelated fashion to hypoxia. a Intravascular partial pressure of $\mathrm{O}_{2}\left(\mathrm{pO}_{2}\right)$ drops as oxygen is unloaded from haemoglobin in red blood cells (RBCs) as they traverse distally from feeding arterioles; this is termed a longitudinal oxygen gradient. The distance that oxygen can diffuse radially from a vessel is dependent on how much oxygen is present in the vessel. The extent and severity of hypoxia surrounding blood vessels will become more severe as intravascular $\mathrm{pO}_{2}$ drops. b $\mid$ At the extreme, red blood cells lose virtually all oxygen and there is no oxygen available to diffuse out into the tumour. c| Shunt flow diverts blood around the tumour, stealing nutrients from the tumour bed. d | Low vascular density creates hypoxia in extravascular tumour tissue because of limitations on the diffusion distance of oxygen once it leaves the blood vessel. e | Blood vessels that are haphazardly oriented will be less efficient in supplying adequate oxygen to all regions of tissue. $\mathbf{f}$ | Oxygen consumption rate is the most dynamic feature of oxygen transport in tumours. Small changes in demand for oxygen create large changes in the extent and severity of hypoxia, because higher demand not only limits the diffusion distance of oxygen, it also more severely depletes vessels of oxygen, thereby exacerbating longitudinal oxygen gradients ${ }^{155} \cdot \mathbf{g}$ | Intravascular hypoxia reduces red blood cell deformability, increasing blood viscosity, which in turn reduces flow rate ${ }^{96}$. Relative oxygen concentrations are colour-coded. The direction of blood flow is from the red vessel(s) to the blue vessel(s) as indicated by the grey arrows. These diagrams provide a general pictorial depiction of these basic features. In reality, within any tumour there are microregional variations in oxygenation, with oxygen concentration decreasing radially from microvessels (FIG. 3). 


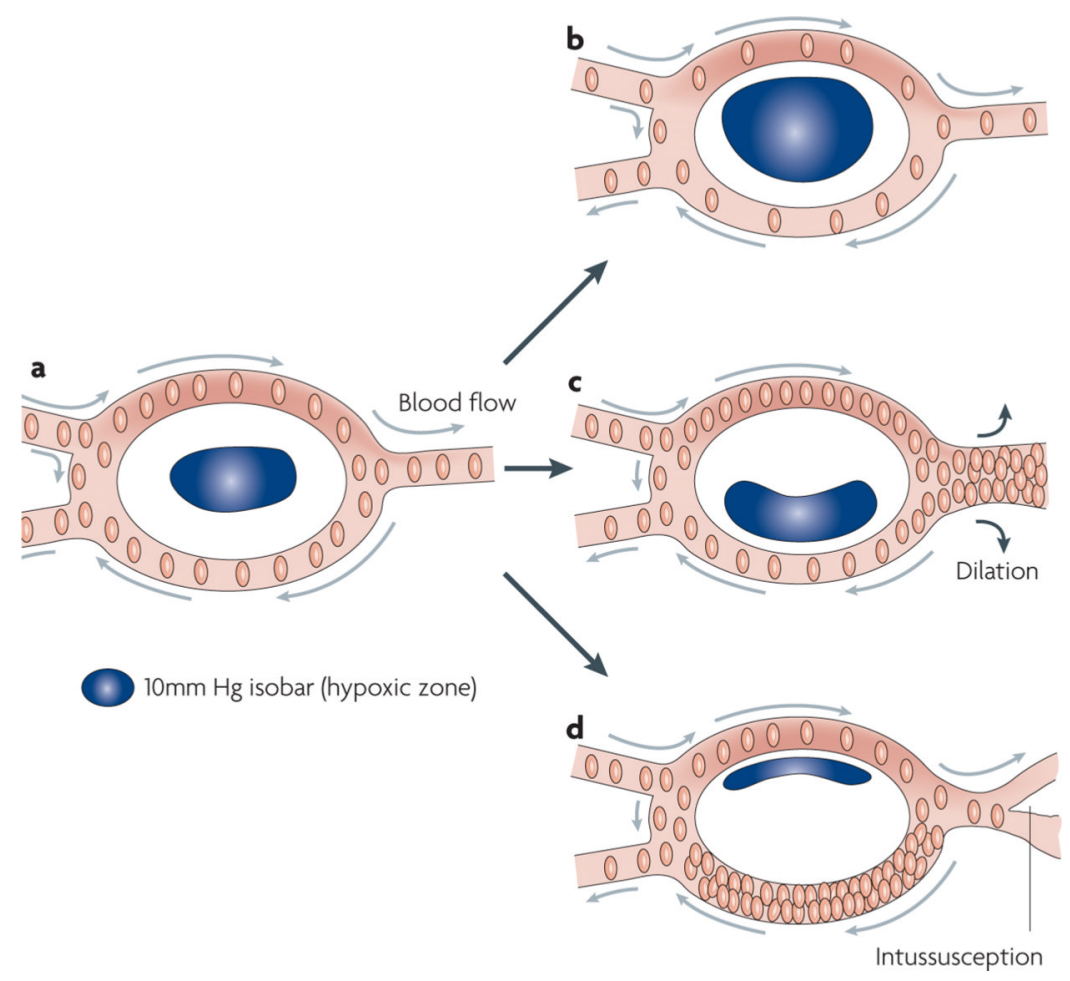

Figure 3. Composite model for the effect of cycling tumour hypoxia on radial diffusion of oxygen In this figure, the effect of four different types of change in red cell flux (the primary determinant of oxygen delivery) on the location and severity of hypoxia are depicted within a tumour microregion. a The baseline case depicts balanced red cell fluxes in all microvessels. The hypoxic zone, defined in this discussion as regions where the partial pressure of $\mathrm{O}_{2}\left(\mathrm{pO}_{2}\right)<10 \mathrm{mmHg}$, is centrally located. $\mathbf{b} \mid$ If the red cell flux drops by an equal proportion in all microvessels, the size and severity of the hypoxic zone will increase, but it will still be centrally located. Spontaneous fluctuations in red blood cell flux within small networks such as this have been shown to change the oxygen gradient, creating a switch from a to $\mathbf{b}$, on a timescale of $1-3$ cycles per hour ${ }^{81}$. $\mathbf{c} \mid$ Vasodilation of a downstream vessel steals red blood cells from the bottom segment, because flow resistance is much less in the dilated vessel. This change will shift the hypoxic zone downward. This may occur during the process of ongoing angiogenesis. d | Vascular remodelling (here indicated by intussusception) changes the flow resistance in the split downstream vessel, diverting flow upstream. This will reduce the hypoxic zone and shift the gradient upward. If the $\mathrm{pO}_{2}$ of the blood entering the microregion is higher overall, then the effects of these shifts will be less apparent on the tumour cells in terms of severity of hypoxia. If the $\mathrm{pO}_{2}$ of the blood entering the microregion is lower, then the severity will be greater. Vascular remodelling and/or variations in shunt flow can also alter the extent and severity of hypoxia from day to day, by changing the oxygen delivery to the tumour microregion. 


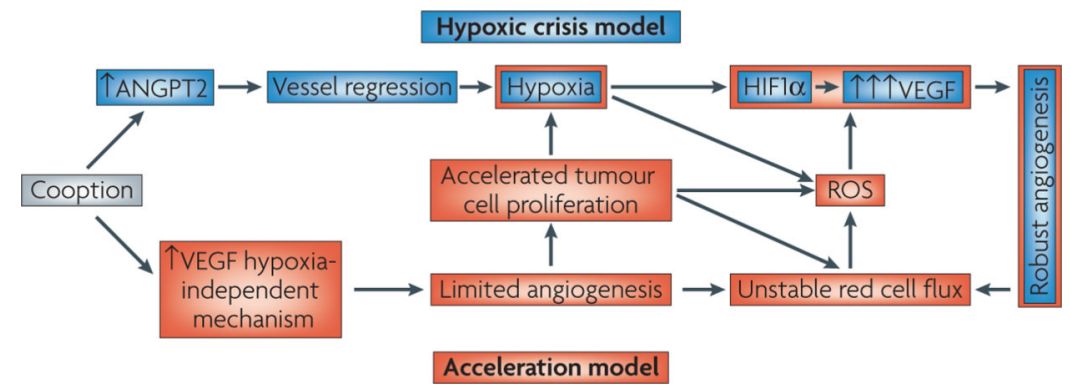

Figure 4. Models for role of hypoxia in initiation and acceleration of angiogenesis

The vascular crisis model was hypothesized by Holash et al. to explain how hypoxia leads to angiogenesis initiation. It is characterized by an early overexpression of angiopoietin 2 (ANGPT2) in the absence of vascular endothelial growth factor (VEGF), which leads to vascular regression and hypoxia. Once hypoxia occurs, VEGF is upregulated, promoting initiation of angiogenesis ${ }^{109}$. The acceleration model was hypothesized by Cao et al. ${ }^{97}$. In this model, hypoxia is not responsible for initiation of angiogenesis; rather it is driven by non-hypoxia-mediated mechanisms, such as VEGF upregulation by oncogenes. Once angiogenesis is initiated, proliferation of tumour cells occurs, creating hypoxia. Hypoxiainducible factor 1 (HIF1) is then upregulated to accelerate angiogenesis. Both models incorporate the concept of cooption before angiogenesis and both emphasize the importance of hypoxia in robust and disregulated angiogenesis. The two models converge on a cycle of unchecked angiogenesis, keyed by instability in perfusion, reactive oxygen species, hypoxia and persistent HIF1 activity. Further work is needed to establish how accurate these models are in both primary and metastatic tumour models. 


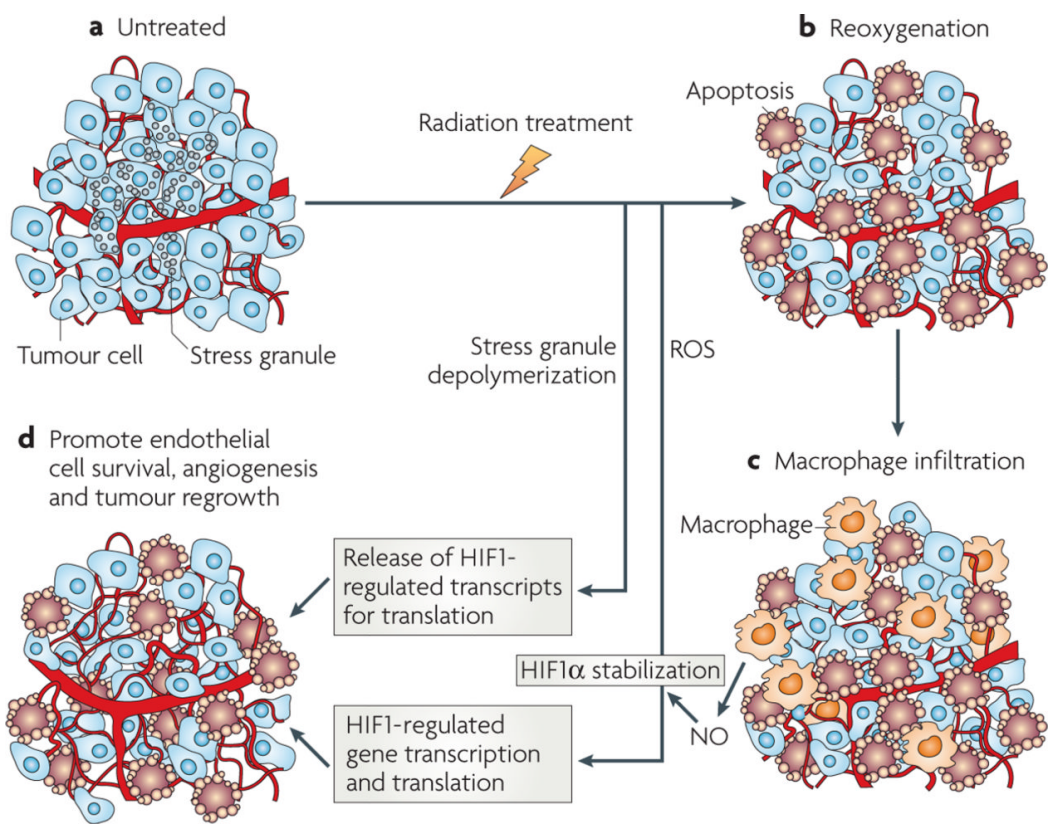

Figure 5. Mechanisms for hypoxia-inducible factor 1 (HIF1) upregulation and consequences after radiation therapy

a Untreated tumours often have hypoxic subregions. In hypoxic regions, stress granules form containing HIF1-mediated transcripts, sequestering the transcripts from being translated into protein. $\mathbf{b}$ | After radiation treatment, better oxygenated cells die and there is an increase in perfusion, leading to reoxygenation of the previously hypoxic cells. Stress granules disaggregate, releasing HIF1-regulated mRNAs, which can then go on to be translated into protein. Reoxygenation also causes hypoxia-reoxygenation injury, causing byproduction of reactive oxygen species (ROS), which stabilize HIF1a, even in the presence of improved oxygenation. $\mathbf{c}$ Macrophages are attracted to the dying tumour cells, become activated and release nitric oxide (NO), which also stabilizes HIF1a. d | The increase in HIF1 activity increases vascular endothelial growth factor (VEGF) levels, promoting endothelial cell survival, angiogenesis and tumour cell survival and proliferation. This is highly simplified. Reoxygenation does not completely eliminate hypoxia and there are oxygen gradients within tumours as opposed to categorical differences between aerobic and hypoxic cells. 